\title{
P wave anisotropy caused by partial eclogitization of descending crust demonstrated by modelling effective petrophysical properties
}

\author{
This is a non peer-reviewed preprint from earthArxiv, submitted to Geochemistry, Geophysics, \\ Geosystems
}

\section{Sascha Zertani $^{1 *}$, Johannes C. Vrijmoed ${ }^{1}$, Frederik Tilmann ${ }^{1,2}$, Timm John ${ }^{1 *}$, Torgeir B. Andersen $^{3}, \&$ Loic Labrousse ${ }^{4}$}

${ }^{1}$ Institute of Geological Sciences, Freie Universität Berlin, 12249, Berlin, Germany.

${ }^{2}$ Deutsches GeoForschungsZentrum, 14473, Potsdam, Germany.

${ }^{3}$ The Centre of Earth Evolution and Dynamics (CEED), Department of Geosciences, University of Oslo, 0316 Oslo, Norway.

${ }^{4}$ Sorbonne Université, CNRS-INSU, Institut des Sciences de la Terre Paris, ISTeP, UMR 7193, F-75005 Paris, France.

Corresponding authors:

Sascha Zertani, Department of Geosciences, Freie Universität Berlin, Malteserstr. 74-100,

12249, Berlin, Germany. E-mail address: sascha.zertani@ fu-berlin.de. Telephone: +49 30838 75782.

and

Timm John, Department of Geosciences, Freie Universität Berlin, Malteserstr. 74-100, 12249, Berlin, Germany. E-mail address: timm.john@fu-berlin.de. Telephone: +49 3083870103.

\section{Key Points:}

- Eclogitization of crustal rocks causes significant anisotropy on a crustal scale

- External geometric arrangement has no significant influence on effective seismic properties

- Backazimuthal bias in receiver function studies can be caused by eclogitization 


\begin{abstract}
Seismological studies of large-scale processes at convergent plate boundaries typically probe lower crustal structures with wavelengths of several kilometers, whereas field-based studies typically sample the resulting structures at a much smaller scale. To bridge this gap between scales, we derive effective petrophysical properties on the $20-\mathrm{m}, 100-\mathrm{m}$, and kilometer scales based on numerical modelling with the Finite Element Method. Geometries representative of eclogitization of crustal material are extracted from the partially eclogitized exposures on Holsnøy (Norway). We find that the $\mathrm{P}$ wave velocity is controlled by the properties of the lithologies rather than their geometric arrangement. $\mathrm{P}$ wave anisotropy, however, is dependent on the fabric orientation of the associated rocks, as fabric variations cause changes in the orientation of the initial anisotropy. As a result, different structural associations can result in effective anisotropies ranging from $\sim 0-4 \%$ for eclogites not associated with ductile deformation to up to $8 \%$ for those formed during ductile deformation. For the kilometer-scale structures, a scale that in principle can be resolved by seismological studies, we obtained $\mathrm{P}$ wave velocities between 7.7 and $8.0 \mathrm{~km} \mathrm{~s}^{-1}$. The effective $\mathrm{P}$ wave anisotropy on the kilometer-scale is $\sim 3-4 \%$ and thus may explain the backazimuthal dependence of seismological images of, for example, the Indian lower crust currently underthrusting beneath the Himalaya. These results imply that seismic anisotropy could be the key to visualize structures in active subduction and collision zones that are currently invisible to geophysical methods and thus can be used to unravel the underlying processes active at depth.
\end{abstract}

\title{
1. Introduction
}

Convergent plate boundaries are among the most important sites of crustal reorganization and element recycling. There, crustal material is buried to great depths, recycled into the mantle, integrated into orogenic roots and in some cases also exhumed back to the surface. All of these processes result in the modification of crustal rocks through metamorphism and brittle and/or ductile deformation. However, this occurs at depths inaccessible to direct observation. Thus, such structures are either studied by geophysical imaging methods or by investigating exhumed rocks that have been metamorphosed and/or deformed in the past (e.g., Austrheim, 1987; Rondenay et al., 2008). Field-based studies of deep processes are restricted to rare exposures where mineral assemblages and structures are not substantially overprinted during exhumation (e.g., Austrheim, 1987; John \& Schenk, 2003). In order to properly interpret seismic velocities and deduce the ongoing metamorphic processes associated with large-scale tectonics we require 
knowledge of how seismic properties change with depth and lithology (e.g., Kind et al., 2012; Rondenay et al., 2008).

While field-based studies include information down to the micron scale, geophysical imaging techniques employ wavelengths that are only sensitive to kilometer-scale structures (e.g., Bloch et al., 2018; Kim et al., 2019). In addition, the resolution of geophysical imaging is often further limited by the available station coverage and distribution of signal sources. This creates a large gap between the scale at which we image structures with geophysical methods and the scale at which we can observe structures in the field. Subsequently, seismic velocities that are measured in the laboratory or calculated for individual samples may not be representative of the properties of lithological and structural associations on a larger scale. As these structures are smaller than the resolution of seismological methods the properties of the different constituents will act together as one effective medium (e.g., Backus, 1962; Hudson, 1981; Okaya et al. 2019). Specifically, eclogitization processes occurring at depth remain difficult to assess, although they are suspected to play a major role in geodynamic processes (Austrheim, 1991; Dewey et al., 1993; Yamato et al., 2019). Eclogitization causes a density increase of crustal material that decreases buoyancy forces and significantly adds to driving forces (e.g., slab pull) at convergent plate boundaries (e.g., Hetényi et al., 2007; Klemd et al., 2011). However, the same density increase also significantly complicates the detection of eclogites at depth as it is combined with an increase of the elastic moduli of the rock. Subsequently, the resulting seismic properties of eclogites become similar to those of mantle peridotites. This makes distinction between the mantle and crust at depth difficult (e.g., Bostock, 2013; Hetényi et al., 2007; Rondenay et al., 2008; Yuan et al., 2000). Nevertheless, partially eclogitized material within a subducting slab shows a range of geometric configurations and orientations of anisotropy in the constituent 
lithologies, depending on conditions during formation (John \& Schenk, 2003; Scambelluri et al., 1995; Zertani et al., 2019b). It is therefore not necessarily straightforward to transform a measured velocity into a degree of eclogitization.

Eclogites formed from dismembered parts of the subducting crust, for example at the plate interface, often occur as undeformed boudins in a weaker matrix, typically composed of metasediments (e.g., Hetzel et al., 1998; Pleuger et al., 2005) or serpentinites (e.g., Scambelluri et al., 1995). On the other hand, field-based studies have shown that intra-slab eclogitization of crustal rocks is often associated with fluid availability that enhances mineral reactions and ductile deformation, first forming centimeter-thick shear zones (Austrheim, 1987; John \& Schenk, 2003). As eclogitization and deformation progress, such shear zones can widen and connect into larger shear zone networks surrounding low-strain domains (e.g., Jolivet et al., 2005) and the shear zones can ultimately reach a thickness of a few hundred meters (Angiboust et al., 2011; Boundy et al., 1997; Raimbourg et al., 2005; Zertani et al., 2019b). In exposed examples of coherent pieces of partially eclogitized crust, the preserved shear zones rarely reach scales that can be resolved with geophysical methods and the complex associations would thus act as an effective medium at depth (e.g., Zertani et al., 2019a).

In contrast, geophysical imaging methods are used to study large-scale processes active at great depth in collision and subduction zones (e.g., Halpaap et al., 2018). To unravel structures caused by metamorphism coeval with deformation, the receiver function method is of specific interest. It is based on the conversion of $\mathrm{P}$ to $\mathrm{S}$ waves and vice versa at boundaries with contrasting impedance and therefore mostly sensitive to structural boundaries (Kind et al., 2012). For example, Schneider et al. (2013) imaged a low velocity zone below the Pamir corresponding to the subducting lower continental crust of the Eurasian Plate. The velocity contrast of this zone 
107 with respect to the surrounding mantle, however, decreases below a depth of $\sim 100 \mathrm{~km}$,

108 suggesting eclogitization of the down going crust. Nabelek et al. (2009) and Schulte-Pelkum et

109 al. (2005) observed a backazimuthal dependence of the retrieved signal in the lower crust of

110 India beneath the Himalaya that suggests a significant large-scale anisotropic fabric within the

111 lower continental crust of India.

112 Direct estimates of seismic velocities are usually derived from samples that are only a few

113 centimeters in size (e.g., Kern et al., 1996) and extrapolation to scales that are resolvable using

114 geophysical methods relies on poorly supported assumptions, mainly that the composition of the

115 samples is representative of the crust at geophysically relevant scales and that the large-scale

116 organization of lithologies has no relevance. Voigt-Reuss-Hill averaging is the standard method

117 to calculate velocities within a medium based on the abundance of individual mineral phases

118 resulting in an average (isotropic) seismic velocity (Hill, 1952). The classic Backus averaging

119 allows calculation of the effective anisotropy of a finely layered medium. It is valid under the

120 assumption that the thickness of individual layers is far smaller than the seismic wavelength

121 (Backus, 1962). Although such averaging schemes are widely used to constrain seismic

122 velocities of various rocks, their capabilities are limited because they are only valid for simple

123 geometries that generally do not capture the structural complexity of real rocks.

124 To assess these simplifying assumptions, it is necessary to utilize a more sophisticated approach.

125 As a first step in this direction, we focus on the calculation of effective $\mathrm{P}$ wave velocities of

126 eclogite-facies associations using a technique based on stress calculations, for a variety of

127 representative geometries. The simplified geometries are derived from field observations on the

128 island of Holsnøy in the Bergen Arcs (Norway), where a $>70 \mathrm{~km}^{2}$ large complex of partially 
eclogitized lower continental crust is exposed that provides an excellent coherent laboratory to

130 study the geometries that are established during eclogitization.

131

\section{Geological Setting}

The exposed lower continental crust on the island of Holsnøy (Bergen Arcs, western Norway)

has been partially eclogitized during the Caledonian orogeny (Austrheim, 1991). The rocks

belong to the Lindås nappe, which together with the Dalsfjord and Jotun nappe complexes

represents the lower crust of the former Jotun microcontinent that constituted part of the pre-

Caledonian hyperextended margin of Baltica (Andersen et al., 2012; Jakob et al., 2019). The

Lindås nappe is for a large part composed of anorthositic granulites that experienced Proterozoic granulite-facies P-T conditions of $\sim 1 \mathrm{GPa}$ and $\sim 800{ }^{\circ} \mathrm{C}$, at $\sim 950 \mathrm{Ma}$ (Austrheim \& Griffin, 1985). The P-T conditions in the following 500 M.y. are unclear. The rocks, however, show no signs of significant alteration before the Scandian Caledonian collision and likely cooled to conditions reflecting mid to lower crustal conditions (Jamtveit et al., 1990).

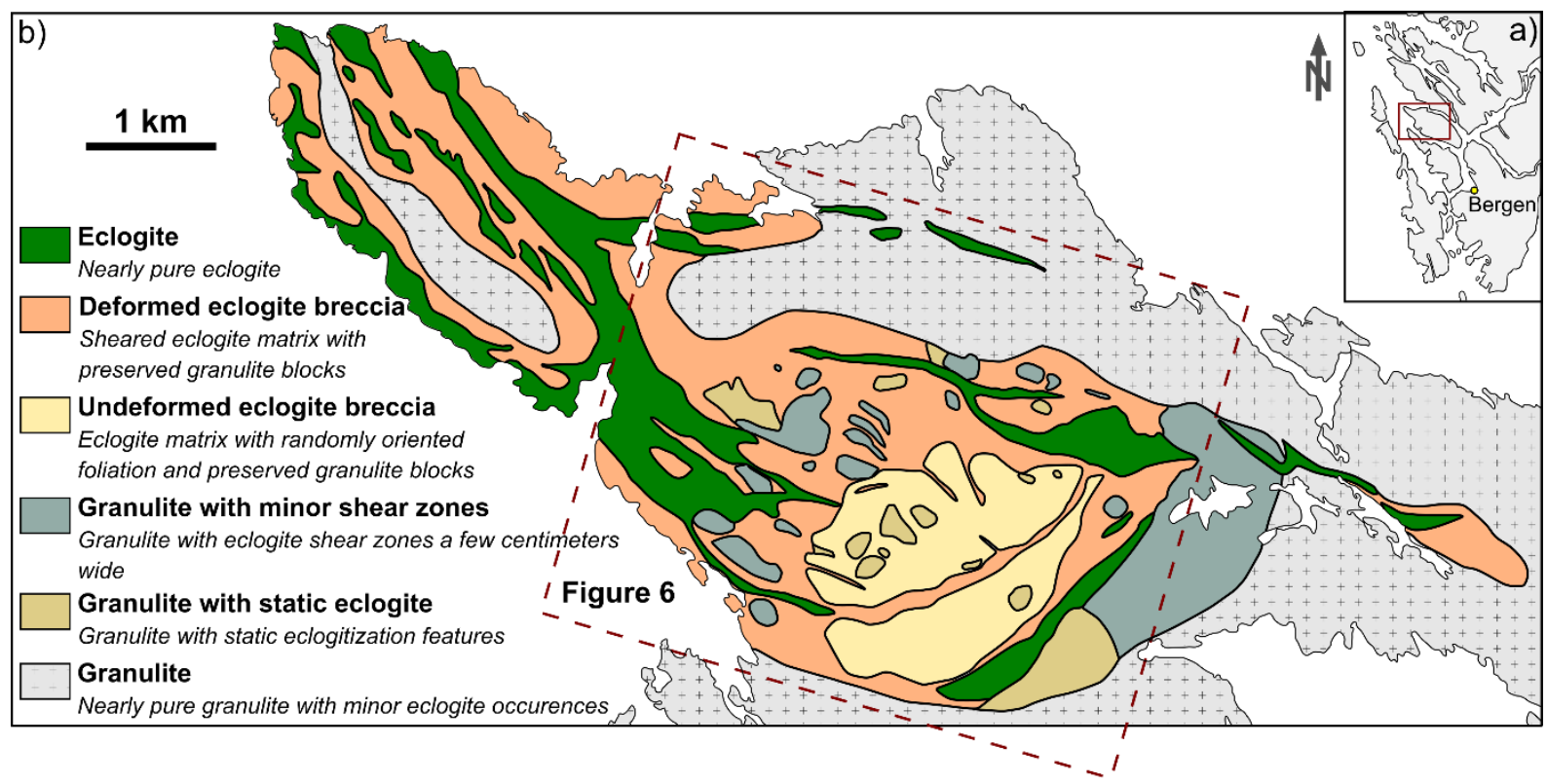

Fig. 1. Geological map of northwestern Holsnøy (modified from Jolivet et al. (2005) and Zertani et al. (2019b)). The inset (a) shows the location of Holsnøy in western Norway. 
During the Caledonian collision the Jotun microcontinent constituted the leading edge of Baltica, which was integrated into the collision wedge as the lower plate (Corfu et al., 2014). Subsequently, the Lindås nappe was subjected to peak eclogite-facies conditions of $\sim 2 \mathrm{GPa}$ and $\sim 750{ }^{\circ} \mathrm{C}$ at $429 \mathrm{Ma}$ (Bhowany et al., 2018; Glodny et al., 2008; Jamtveit et al., 1990; Zhong et al., 2019). Large volumes of the dry granulite-facies rocks, however, remained metastable and were thus preserved (Austrheim, 1987; Jackson et al., 2004). Eclogitization is linked to fluid availability and was facilitated along shear zones but also progressed into the rock volume as a static overprint (Austrheim, 1987; Zertani et al., 2019b). Fluid infiltration was likely initiated via brittle fractures, which provided fluid pathways within an otherwise dry rock (Austrheim, 1990; Jamtveit et al., 1990).

This heterogeneously distributed transformation resulted in a complex mixture of eclogites and granulites (Fig. 1). The resulting lithologies can be divided into six categories based on the abundance of eclogite and the associated structural relationships (Boundy et al., 1992; Zertani et al., 2019b). Next to the mostly unaltered granulite (<20\% eclogite), small-scale eclogitization features are distinguished into granulites cut by eclogite-facies shear zones a few centimeters wide and granulites with eclogitized patches that are not associated with ductile deformation (both $20-50 \%$ eclogite). With progressive eclogitization these evolve into the so-called eclogite breccia, which can be described by two endmembers: sheared eclogite breccia composed of a strongly sheared eclogite matrix containing preserved granulite blocks and unsheared eclogite breccia, where the eclogite matrix was not subjected to pervasive ductile deformation (50-90\% eclogite). Ultimately, shear zones evolve that are up to a few hundred meters thick and are almost entirely composed of eclogite with little to no preserved granulite ( $>90 \%$ eclogite).

\section{Model Setup}




\subsection{Finite element calculations}

The aim of this study is to obtain effective $\mathrm{P}$ wave velocities and the corresponding $\mathrm{P}$ wave anisotropy from variably eclogitized lower crustal rocks based on observed 2D geometric arrangements that act as an effective medium. The information extracted in the field is simplified and translated into numerical models with the goal of capturing the most essential properties of the observed field relationships. As the field observations along approximately planar exposures would require the introduction of essentially arbitrary additional parameters to create plausible three-dimensional models, this contribution focuses on 2D numerical modelling. Whereas this approach inevitably results in some differences in the inferred seismic velocities (compared to what would be obtained for the unknown true three-dimensional structure, the $2 \mathrm{D}$ models nevertheless are expected to provide a good approximation and therefore enhance our understanding of how geometries affect petrophysical properties from the outcrop to the map scale. It has to be noted that here we focus on $\mathrm{P}$ waves, as in our formulation the out-of-plane polarization of $\mathrm{S}$ waves is not included.

Both the effective medium and the individual rock types are treated as linear elastic anisotropic material for which Hooke's law gives the relationship between stress $\left(\sigma_{\mathrm{ij}}\right)$ and strain $\left(\varepsilon_{\mathrm{kl}}\right)$ :

$$
\sigma_{i j}=c_{i j k l} \varepsilon_{k l}
$$

In $2 \mathrm{D}$ the $2 \times 2 \times 2 \times 2$ elastic tensor, which we represent by a symmetric 3 -by-3 matrix in Voigt notation (using the mapping $11 \rightarrow 1,22 \rightarrow 2$ and $12 \rightarrow 3$ ), is sufficient to fully describe the in-plane anisotropy:

$$
\left[\begin{array}{lll}
c_{11} & c_{12} & c_{13} \\
c_{21} & c_{22} & c_{23} \\
c_{31} & c_{32} & c_{33}
\end{array}\right]
$$

Due to symmetry considerations $\mathrm{c}_{13}, \mathrm{c}_{23}, \mathrm{c}_{31}$, and $\mathrm{c}_{32}$ are expected to be zero, and $\mathrm{c}_{12}$ should be equal to $c_{21}$. One way of obtaining the effective properties is to run numerical experiments 
192 solving the elasto-dynamic wave equations and recording the time necessary for a wave to travel 193 through the medium (e.g., Saenger et al., 2004). Other studies have used asymptotic expansion

194 homogenization to calculate the effect of mineral orientation on seismic anisotropy solving for 195 the 6x6 elastic tensor in 3D (Naus-Thijssen et al., 2011a; 2011b; Vel et al., 2016). Alternatively, 196 we calculate the $\mathrm{P}$ wave velocities from the elastic tensor of the effective medium using the 197 formulas for transversely isotropic media (Mavko et al., 2009):

$$
V_{P}=\left(c_{11} \sin ^{2} \theta+c_{22} \cos ^{2} \theta+c_{33}+\sqrt{M}\right)^{\frac{1}{2}}(2 \rho)^{-1 / 2}
$$

199 200

where:

$$
M=\left[\left(c_{11}-c_{33}\right) \sin ^{2} \theta-\left(c_{22}-c_{33}\right) \cos ^{2} \theta\right]^{2}+\left(c_{12}-c_{33}\right)^{2} \sin ^{2} 2 \theta
$$

The equations fully describe the $\mathrm{P}$ wave velocity in $2 \mathrm{D}$ because our calculations assume no outof-plane properties, i.e., plane strain. Thus, the reduction of a transversely isotropic medium to $2 \mathrm{D}$, with the symmetry axis within the plane results in an anisotropic medium and is sufficient to describe the anisotropic elastic properties in $2 \mathrm{D}$. The individual components of the $2 \mathrm{D}$ elastic tensor $\left(c_{i j k l}\right)$ of the effective medium are calculated from the stresses and strains calculated in a set of numerical experiments. For this purpose, three experiments (Fig. 2) are performed for each geometric model, applying different boundary conditions: (1) The area of interest is compressed along the $y$ axis along the upper and lower boundary by imposing a fixed displacement. Along the left and right boundary displacement in x direction is zero. (2) The medium is compressed horizontally, that is, along the $\mathrm{x}$ axis. In this case displacement in $\mathrm{y}$ direction is zero along the top and bottom boundary. (3) Finally, simple shear is enforced along the top and bottom boundary, that is, displacement to the right along the top boundary and to the left at the bottom boundary, resulting in shear parallel to the $\mathrm{x}$ axis. A fourth experiment (simple shear parallel to 
214 the y axis) was used for validation and yielded the same results as experiment (3), as is required

215 from the symmetry of the elasticity tensor.

216 The three experiments result in a set of nine equations for six unknown components of the stress

217 tensor, so only 6 of these equations are needed. Due to the setup of each experiment specific

218 strains are zero which allows to simplify the equations to:

$$
c_{21}=\frac{\sigma_{x x}}{\varepsilon_{y y}}, c_{22}=\frac{\sigma_{y y}}{\varepsilon_{y y}} \text {, and } c_{23}=\frac{\sigma_{x y}}{\varepsilon_{y y}}
$$

220 for experiment 1 ,

$$
c_{11}=\frac{\sigma_{x x}}{\varepsilon_{x x}}, c_{12}=\frac{\sigma_{y y}}{\varepsilon_{x x}} \text {, and } c_{13}=\frac{\sigma_{x y}}{\varepsilon_{x x}}
$$

222 for experiment 2, and

$$
c_{31}=\frac{\sigma_{x x}}{\varepsilon_{x y}}, c_{32}=\frac{\sigma_{y y}}{\varepsilon_{x y}} \text {, and } c_{33}=\frac{\sigma_{x y}}{\varepsilon_{x y}}
$$

for experiment 3 .

225 To extract the elastic properties of the effective medium, strain $\left(\varepsilon_{\mathrm{kl}}\right)$ and stress $\left(\sigma_{\mathrm{ij}}\right)$ are averaged across the domain. The boundaries at which the displacement for each of the experiments is enforced are kept far away from the medium of interest to avoid boundary effects. Strain and stress are then averaged only across the domain which constitutes the medium of interest (red in Fig. 2). In the 20-m scale models (Fig. 3a and b) both lithologies are in contact with the inner boundary in some cases. Here the eclogite was extended into the area between inner and outer boundary to avoid edge effects.

232 The $\mathrm{P}$ wave velocities of the effective medium can then be calculated from the resulting 2D

233 elastic tensor. Bulk density is obtained by calculating the mean of the densities weighted by the 234 area of the granulite and eclogite used for the calculation.

235 The calculations are performed using the Galerkin finite element method (FEM) employing an 236 irregular triangular grid. Meshing is done with the mesh generator triangle (Shewchuk, 1996). 
237 Each triangular element consists of six nodes in which the displacement field is calculated with 238 quadratic interpolation and Gauss quadrature integration at three points.

239 The method of obtaining the $\mathrm{P}$ wave velocity described above was tested and benchmarked using

240 an anisotropic layered medium, a problem for which an analytical solution exists (Backus, 1962). Benchmarking was performed on a regular grid and reproduced the analytical solution within machine level precision.

\subsection{Properties of the implemented lithologies}

The physical properties for each element representing the different material are given by the elastic tensor of the corresponding lithology, i.e., granulite or eclogite. Representative elastic tensors were calculated from the velocity measurements (x-z plane) in Zertani et al. (2019a). Those measurements were performed on a true triaxial multi-anvil press using the ultrasonic pulse transmission technique (Kern, 1978) with varying pressure and temperature between ambient conditions and $600 \mathrm{MPa}$ and $600{ }^{\circ} \mathrm{C}$, respectively. From this data, each component can be calculated separately except for $\mathrm{C}_{12}$, as this would require information on the variation of elastic wave speeds along oblique directions not available from laboratory measurements. Therefore, we used the mean $\mathrm{P}$ wave velocity between the $\mathrm{x}$ and $\mathrm{z}$ axis to approximate the velocity of a $\mathrm{P}$ wave travelling at a $45^{\circ}$ angle to the foliation. This results in an almost elliptical anisotropy with the ellipticity parameter $\eta_{\kappa}$ (Brownlee et al., 2017; Kawakatsu, 2016) varying between 0.97 and 1.03. Brownlee et al. (2017) have shown that off-axis anisotropy deviates systematically from elliptical symmetry for rocks with high anisotropy. However, this effect is most pronounced for rocks with high mica and/or quartz contents, which is not the case for the Holsnøy samples shown in Zertani et al. (2019a). The assumption of near-elliptical anisotropy made here is thus in agreement with the scaling laws of the off-axis anisotropy proposed by 
Brownlee et al. (2017). In order to test the relative influence of the intrinsic properties of the constituting lithologies and the geometries themselves, we used two different eclogites and two different granulites (Tab. 1). Because the eclogites measured by Zertani et al. (2019a) were all collected from the main shear zones exposed on Holsnøy, they all have a high $\mathrm{P}$ wave anisotropy. In order to estimate effective properties for statically eclogitized areas, where the eclogite would likely have a lower initial anisotropy, we assumed a lower velocity in x direction for one of the samples (N-101 in Zertani et al., 2019a), thus giving a lower P wave anisotropy of 4\%, which is in accordance with others reported from Holsnøy (Fountain et al., 1994).

Specifically, we chose to use the velocity measured at lower confining pressure (600 MPa). This way, while the velocity is artificially reduced it is still a function of the existing mineral assemblage.

The calculations feature four different categories of structural associations as they are evident from the field (e.g., Austrheim 1987; Raimbourg et al. 2005; Zertani et al., 2019b): (1) granulite with small-scale eclogite shear zones (20-m scale; Figure 3a), (2) granulite with patches of static eclogitization (20-m scale; Figure 3b), (3) sheared eclogite breccia (100-m scale; Figure 3c), and (4) unsheared eclogite breccia (100-m scale; Figure 3d). For each of the categories a series of calculations was performed systematically varying the main configurations that can be observed in the field. These are: a) abundance of eclogite (10-50\% eclogite for 20-m scale and 50-90\% eclogite for 100-m scale), b) orientation of the main foliation of the constituting lithologies (Fig. 3, Fig. 4)., and c) strength of the deformation fabric in the lithologies (static vs. dynamic eclogitization; Zertani et al., 2019b). The orientation of the foliation used for the calculations is given in Figure 3 (as sketches) and Figure 4, where XX means that the fast axis and thus the foliation of the two lithologies are parallel and XY that they are perpendicular to each other. The 
strength of the deformation fabric is also given in Figure 3 (in \% anisotropy) and Figure 4 with the notation: E,H - higher-anisotropy eclogite, E,L - lower-anisotropy eclogite, G,H - higheranisotropy granulite, and G,L - lower anisotropy granulite.

The choice of orientation of these lithologies is related to their structural setting. For the smallscale eclogite shear zones the fast axis of the eclogite is oriented parallel to the shear zone and its foliation as would be established during ductile shear (e.g., Bascou et al., 2001). The fast axis of the granulite is oriented either parallel or perpendicular to the shear zone thus representing a situation where the shear zones are established parallel to the foliation of the granulite or perpendicular to it. On Holsnøy, both of these scenarios are present in the field, however, most shear zones develop obliquely to the granulite-facies foliation. The two scenarios introduced into the calculations are thus endmember representations of the chosen field example. Patches of statically eclogitized material on the other hand typically develop parallel to the granulite foliation. For those calculations the fast axis of the granulite and subsequently the foliation is horizontal. The fast axis of the eclogite is either parallel to the granulite foliation as typically observed in the field or perpendicular to it. We chose to include this case as field observations suggest that static eclogitization features can also crosscut the granulite foliation, specifically in cases where the abundance of eclogite is large enough for individual granulite blocks to start moving independently. This setup thus also represents endmember scenarios. Finally, for the 100-m scale calculations of sheared and unsheared eclogite breccia the eclogite foliation is horizontal in the models. For the sheared eclogite breccia this is straightforward, representing the foliation formed during ductile shear. In the case of unsheared eclogite breccia this was done to make comparison between the two easier. The granulite blocks in the sheared case are often aligned nearly parallel to the eclogite foliation with their preserved internal 
(granulite) foliation. However, rotation of these blocks is not always complete, and the granulite

foliation can appear random in some cases. For the unsheared eclogite breccia the granulite

blocks in the field can indeed have all possible orientations. Subsequently, the implemented

orientations of the fast axis of granulite and eclogite also cover the endmember cases of what can

be observed in the field.

Tab. 1. Seismic velocities of the eclogites and granulites used for the FE calculations. The velocities $\left(V_{P}\right.$ and $\left.V_{S}\right)$, densities and anisotropies were taken from Zertani et al. (2019a). The star indicates that $V_{P X}$ of $\mathrm{N}-101$ was adjusted so that an anisotropy of $4 \%$ results (see text). Anisotropy was calculated as $100 *\left(V_{P X}-V_{P Y}\right) / V_{P m e a n}$. Velocities $(V)$ are given in $\mathrm{km} \mathrm{s}^{-1}$, density $(\rho)$ in $\mathrm{kg} \mathrm{m}^{-3}$ and anisotropy (A) in \%.

\begin{tabular}{|c|c|c|c|c|}
\hline \multirow[b]{2}{*}{ Sample } & \multicolumn{2}{|c|}{ eclogite } & \multicolumn{2}{|c|}{ granulite } \\
\hline & $\mathrm{N}-059$ & $\mathrm{~N}-101$ & $\mathrm{~N}-058 \mathrm{~A}$ & $\mathrm{~N}-103$ \\
\hline $\mathrm{V}_{\mathrm{PX}}$ & 8.45 & $8.31 *$ & 7.12 & 7.76 \\
\hline $\mathrm{V}_{\mathrm{PZ}}$ & 7.74 & 8.01 & 6.99 & 7.46 \\
\hline $\mathrm{V}_{\mathrm{S} 1}$ & 4.58 & 4.65 & 3.75 & 4.12 \\
\hline $\mathrm{V}_{\mathrm{S} 2}$ & 4.70 & 4.64 & 3.77 & 4.24 \\
\hline$\rho$ & 3296 & 3483 & 2833 & 3139 \\
\hline$A_{V P}$ & 9 & 4 & 2 & 4 \\
\hline
\end{tabular}
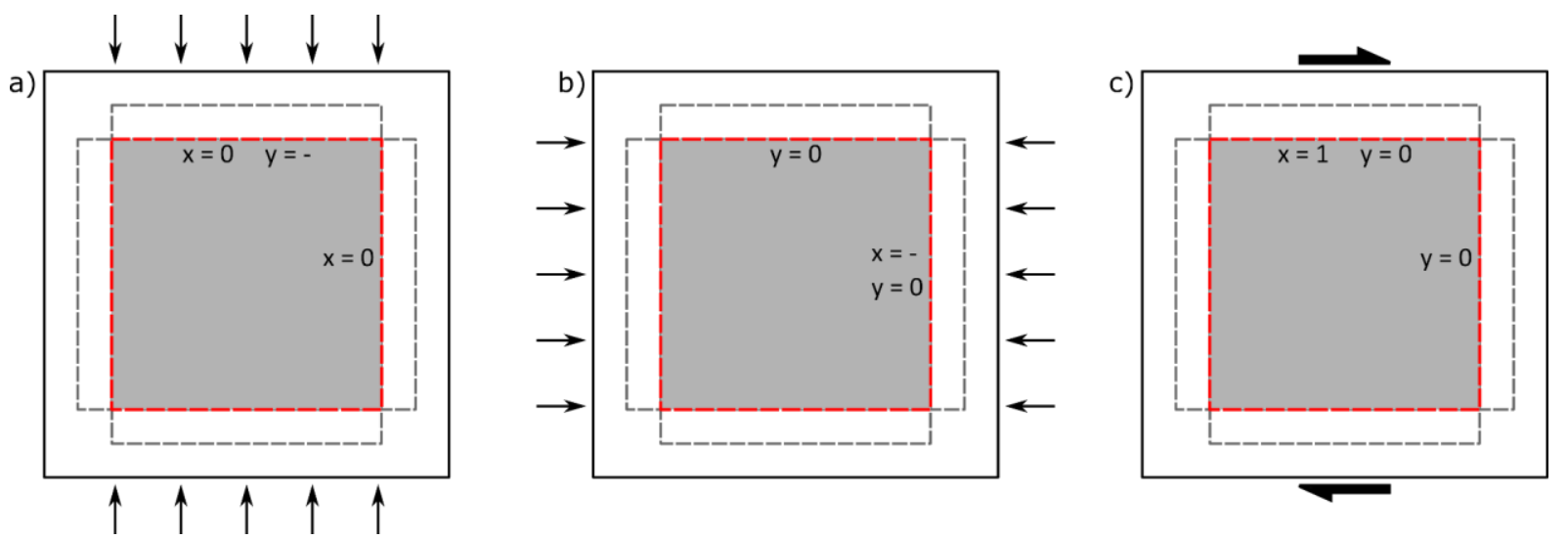

Fig. 2. Illustration of the three experiments with varying boundary conditions conducted for each computation; (a) Vertical compression, (b) horizontal compression, and (c) horizontal simple shear. The grey area represents the medium for which the properties are modelled. The red dotted square represents the boundaries surrounding the domain across which stress and strain are averaged and the grey dashed lines represents the area in which structures were extended if they are in direct contact with the boundary (see text for details). 

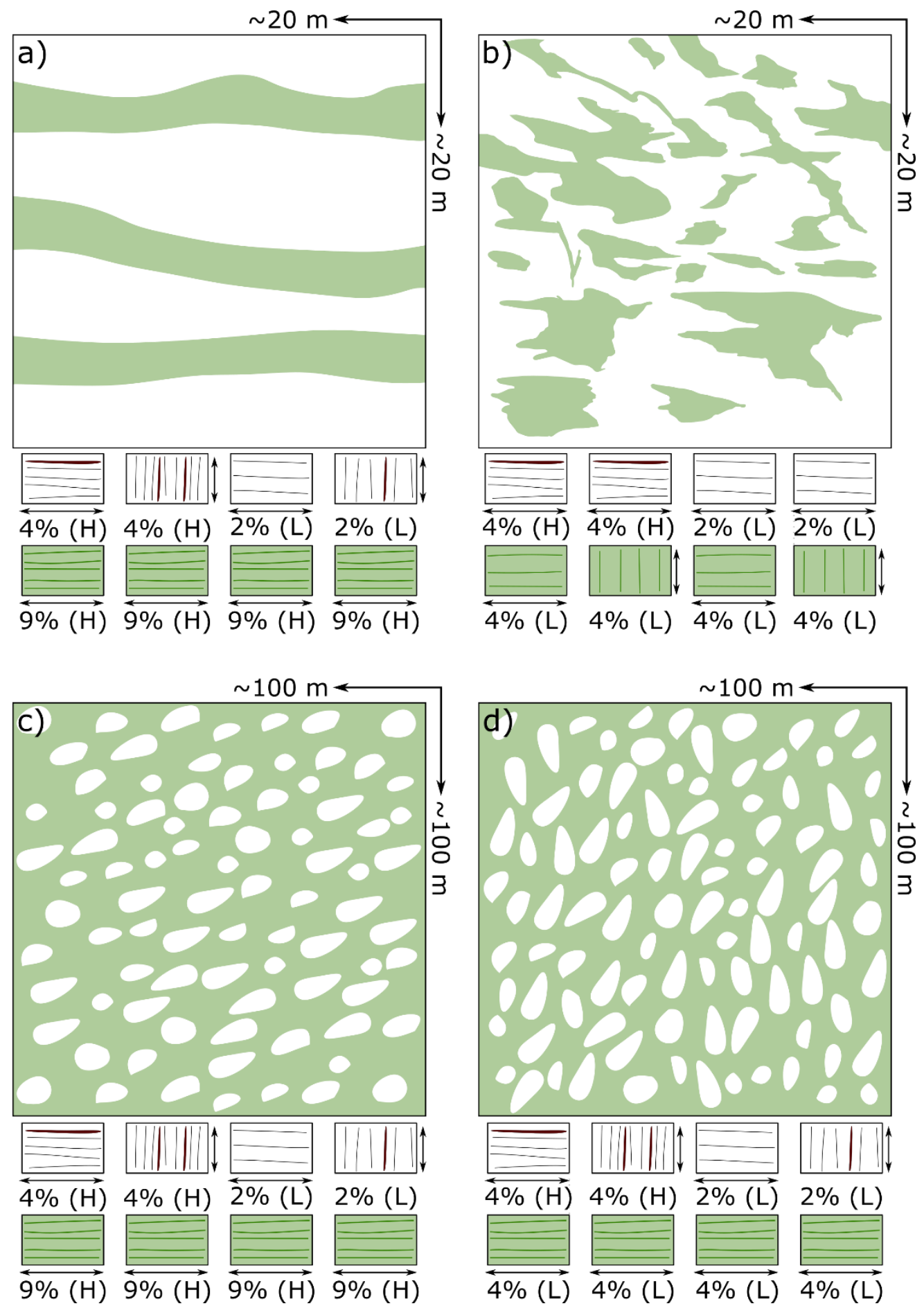

Fig. 3. Examples of the geometries used for the FEM calculations. Eclogite is shown in green and granulite in white. (a) Small-scale eclogite facies shear zones representative of an area of $\sim 20$-by-20 $\mathrm{m}$. The example shown here contains $\sim 30 \%$ eclogite. For the calculations with other eclogite abundances the thickness of the shear zone was varied accordingly. (b) Small-scale static eclogite overprint representative of an area of $\sim 20$-by-20 m. The example shown here contains $\sim 30 \%$ eclogite. For calculations with other eclogite abundances the size of the eclogite patches was varied accordingly. (c) Sheared eclogite breccia with regularily oriented granulite blocks. The example is 
332

333

334

335

336

337

338

339

340

341

342

343

344

345

346

representative of an area of $\sim 100-b y-100 \mathrm{~m}$ and $\sim 70 \%$ eclogite. The size of the granulite blocks remains the same throughout all calculations. To perform calculations with different eclogite abundances the abundance of granulite blocks was altered. (d) Unsheared eclogite breccia with the same variations as in (c). Below each image the corresponding properties of eclogite and granulite used for the calculations are given. Each column represents one model series. The percentage gives the strength of the $P$ wave anisotropy of the corresponding rock and the arrow gives the orientation of the fast $P$ wave direction used for the calculations. $\mathrm{L}$ and $\mathrm{H}$ indicate whether the higher or loweranisotropy version was used.

Tab. 2. Resulting minimum and maximum $P$ wave velocities and $P$ wave anisotropy for each of the calculated models. Velocities are given in $\mathrm{km} \mathrm{s}^{-1}$ and anisotropy is given in \%. For each model the properties of the granulite and eclogite used for the calculation is indicated with the following scheme; L: low-anisotropy, H: high-anisotropy, X: fast axis is oriented horizontally, and Y: fast axis is oriented vertically. 


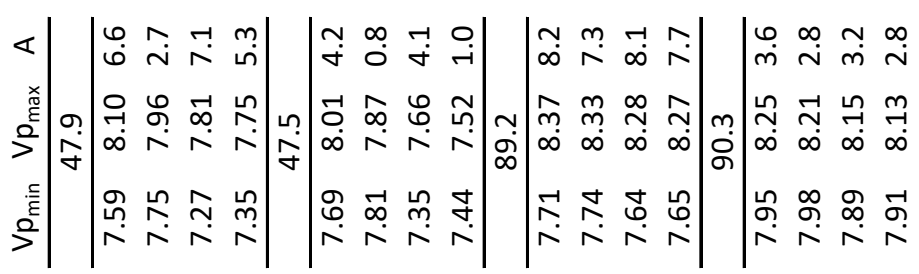

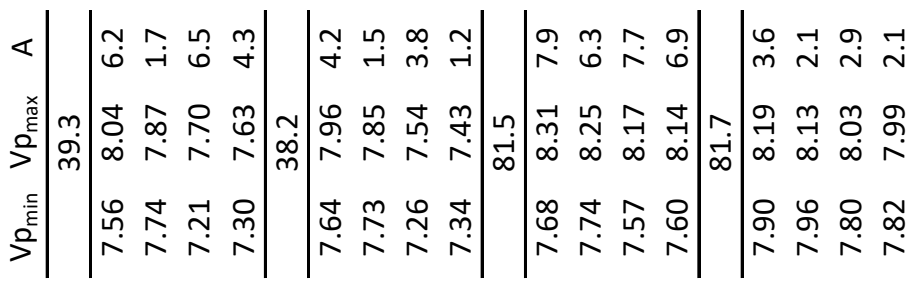

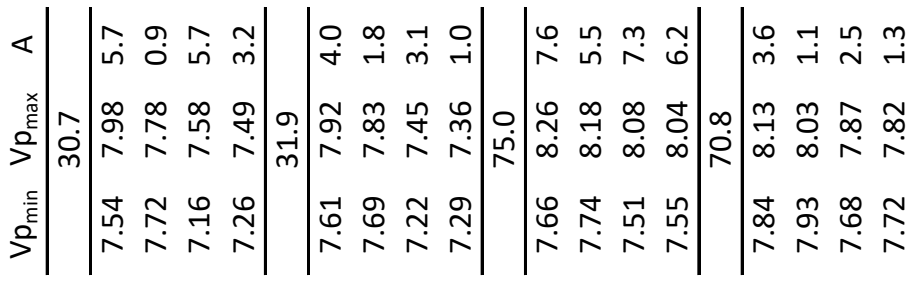

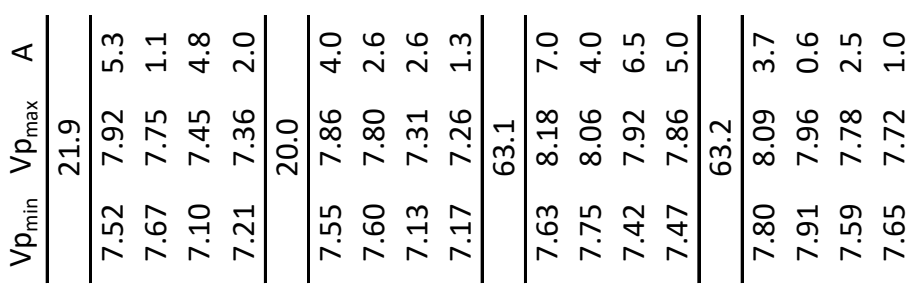

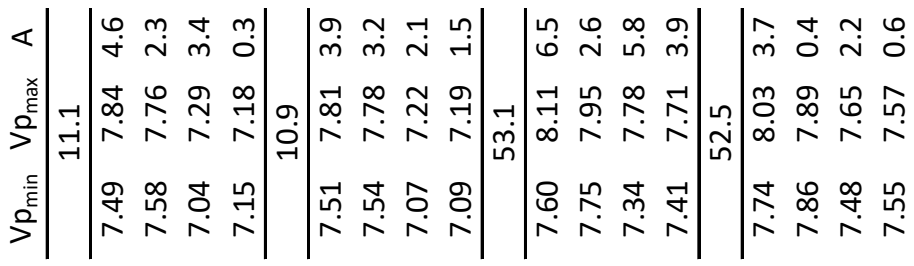

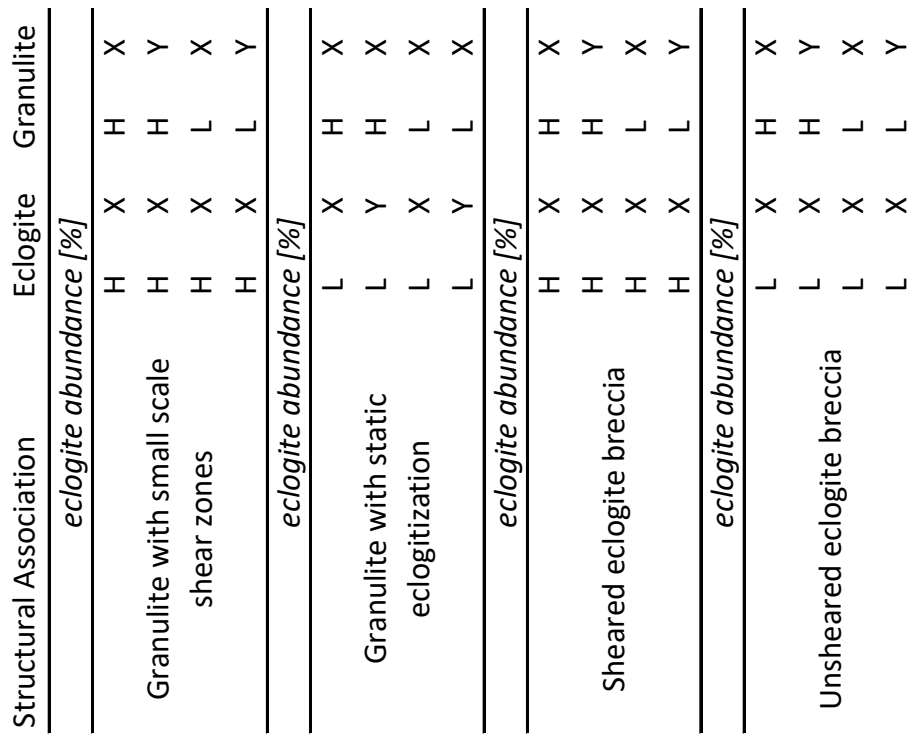




\section{Results}

4.1 P wave velocity and anisotropy of small-scale eclogitization features

The process of eclogitization, as it can be studied on Holsnøy, is driven by two contrasting endmember mechanisms: eclogitization proceeding along shear zones (Fig. 3a) or developing as a static overprint (Fig. 3b). In the first type, eclogitization proceeds along shear zones that widen progressively with time and a wide variety of shear zone thicknesses is found throughout the field area (Austrheim, 1987). Hence, we calculated P wave velocities for 20 examples with varying shear zone thickness as well as varying elastic properties of the eclogite and granulite implemented in the models (Fig. 3, Tab. 2).

Comparing all models shows that the calculated $\mathrm{P}$ wave velocities with higher-anisotropy (stronger deformation fabric) granulites are, in general, higher than those with lower-anisotropy granulites. Furthermore, with increasing shear zone thickness (i.e., amount of eclogite), the P wave velocity in both the slow and the fast $\mathrm{P}$ wave direction increases linearly (Tab. 2; Fig. 4a). The one exception to this trend is given by the models that feature both higher-anisotropy eclogite and the higher-anisotropy granulite, with the fast axis of both rocks oriented perpendicular to each other: the fast axis of the eclogite parallel to the shear zones and the fast axis of the granulite perpendicular to them. For this geometry, the resulting $\mathrm{P}$ wave velocities for the fast and slow axis of the effective medium converge up to an eclogite abundance of $\sim 30 \%$ and then diverge toward higher eclogite abundance. This coincides with a change of the orientations of the fast and slow direction. In this scenario, the velocity perpendicular to the shear zones is almost constant. The velocity parallel to the shear zones, however, increases significantly from 7.58 to $7.96 \mathrm{~km} \mathrm{~s}^{-1}$ with increasing eclogite abundance. The fast axis is thus 
371 perpendicular to the shear zones for an eclogite abundance $<30 \%$ and parallel to the shear zones 372 from $\sim 30-50 \%$ eclogite abundance. The orientation of the slow direction rotates progressively

373 away from the trend of the shear zones, i.e. toward the slow direction of the eclogite. In all other 374 model sequences, the fast direction is parallel to the shear zones and the slow direction is 375 perpendicular.

376 The corresponding $\mathrm{P}$ wave anisotropy also increases with increasing shear zone thickness and 377 reaches a maximum value of $7.1 \%$ (Fig. 5). In most models, this increase is near-linear with 378 increasing eclogite abundance. In contrast, the resulting $\mathrm{P}$ wave anisotropy of those calculations 379 featuring a higher-anisotropy granulite with the fast axis oriented perpendicular to the shear zone 380 decreases between $\sim 10 \%$ and $\sim 30 \%$ eclogite abundance and then increases until $\sim 50 \%$ eclogite 381 abundance. Finally, the $\mathrm{P}$ wave anisotropy at $\sim 50 \%$ eclogite abundance returns to approximately 382 the same value of $\sim 2-3 \%$, as the $\mathrm{P}$ wave anisotropy at $\sim 10 \%$ eclogite abundance.

383 In general, the resulting $\mathrm{P}$ wave anisotropy is larger when the fast axes of both granulite and 384 eclogite are oriented parallel to the shear zone, compared to those examples where the fast axis 385 of the granulite is oriented perpendicular to the shear zone. At lower eclogite abundance the calculations implementing a higher-anisotropy granulite result in a higher anisotropy of the 387 effective medium, while the results at higher eclogite abundance indicate that the anisotropy of 388 the effective medium is higher if the granulite has a lower intrinsic anisotropy (Fig. 5). 
a) Shear zones (20-m scale)

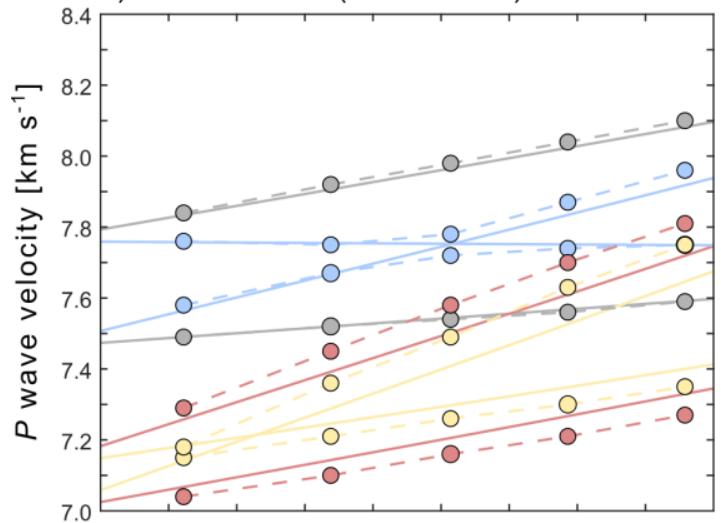

c) Static eclogitization (20-m scale)

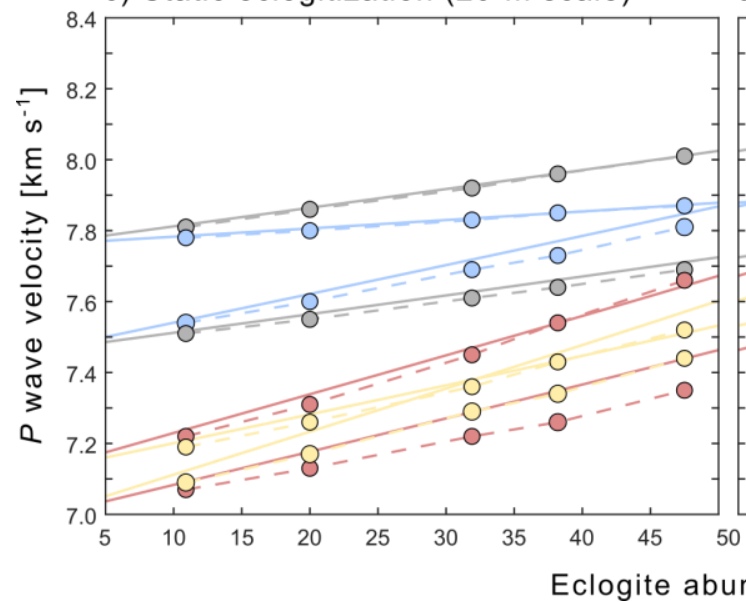

b) Sheared ecl. breccia (100-m scale)

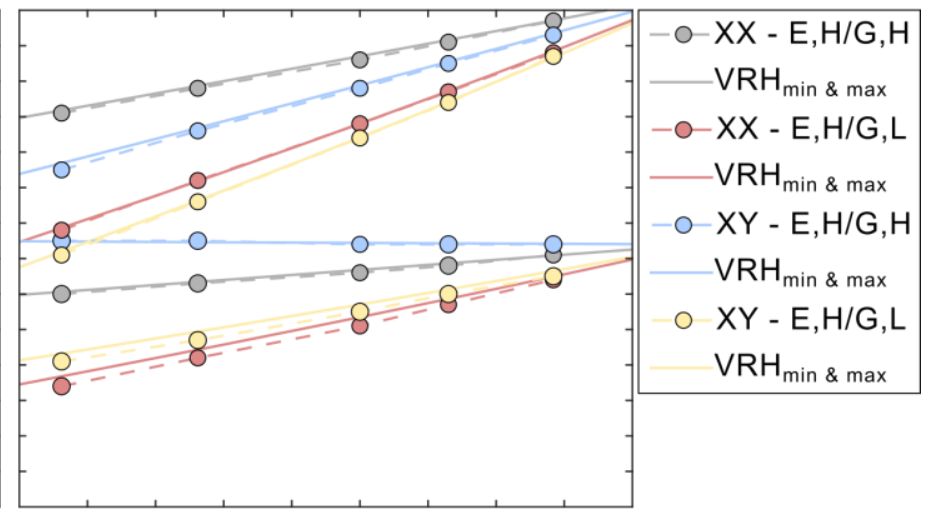

d) Unsheared ecl. breccia (100-m scale)

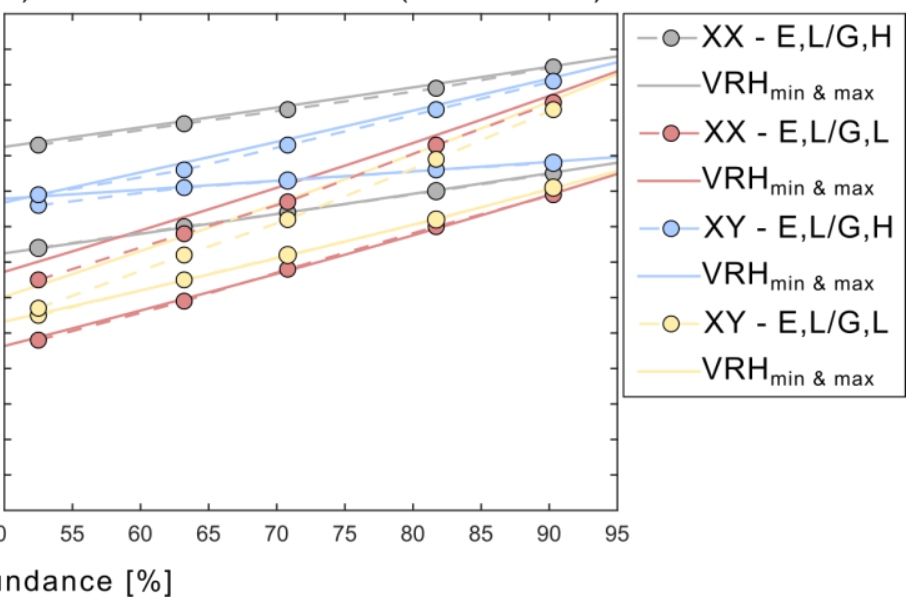

Fig. 4. P wave velocities of the FEM calculations: (a) Small-scale eclogite shear zones, (b) sheared eclogite breccia, (c) small-scale static eclogite, and (d) unsheared eclogite breccia. The legend for (a) and (b) is to the right of (b) and the legend for (c) and (d) is to the right of (d). Each model series is shown by two connecting dashed lines. The upper line represents the maximum velocities and the lower line represents the minimum velocities. The legend is given in the following scheme; XX: foliation and fast axis of granulite and eclogite are parallel, XY: foliation and fast axis of granulite and eclogite are perpendicular (shown as sketches in Figure 3), E,H or E,L: eclogite with high anisotropy or low anisotropy, respectively, G,H or G,L: granulite with high or low anisotropy, respectively. Higher and lower anisotropy is indicated in \% in Figure 3. Solid lines indicate VoigtReuss-Hill averages in the same color scheme as the modeling results averaged from the elastic tensor implemented in the corresponding calculations. Shown are calculated velocities parallel to $\mathrm{x}$ and $\mathbf{y}$. 
a) Shear zones (20-m scale)

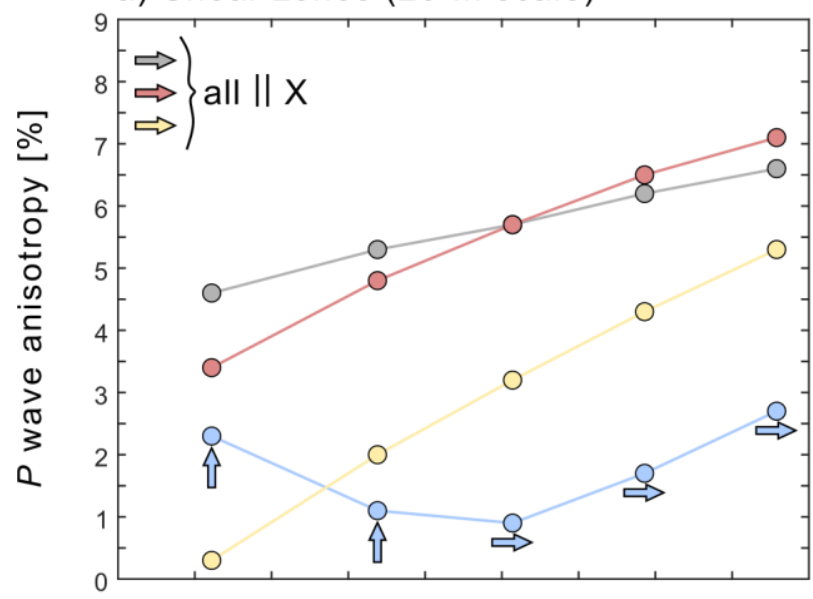

c) Static eclogitization (20-m scale)

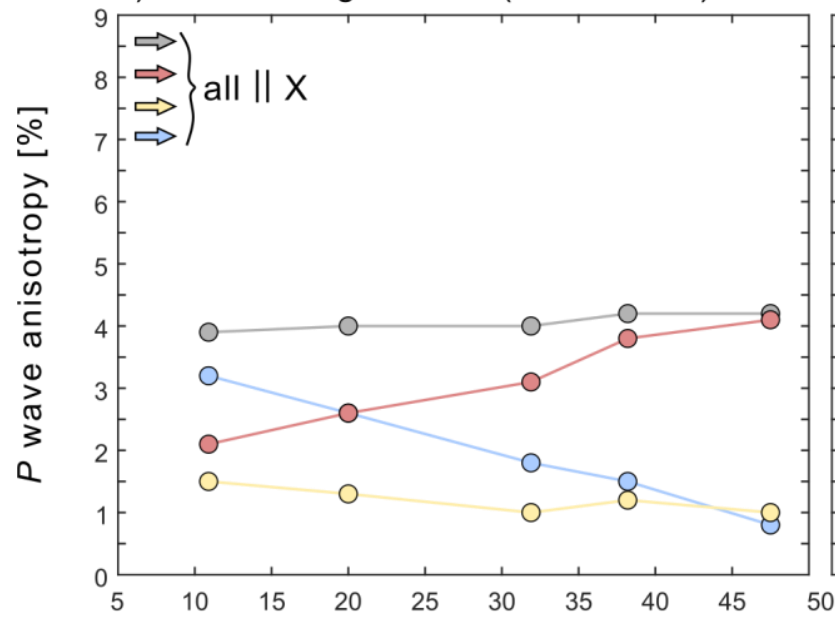

b) Sheared ecl. breccia (100-m scale)

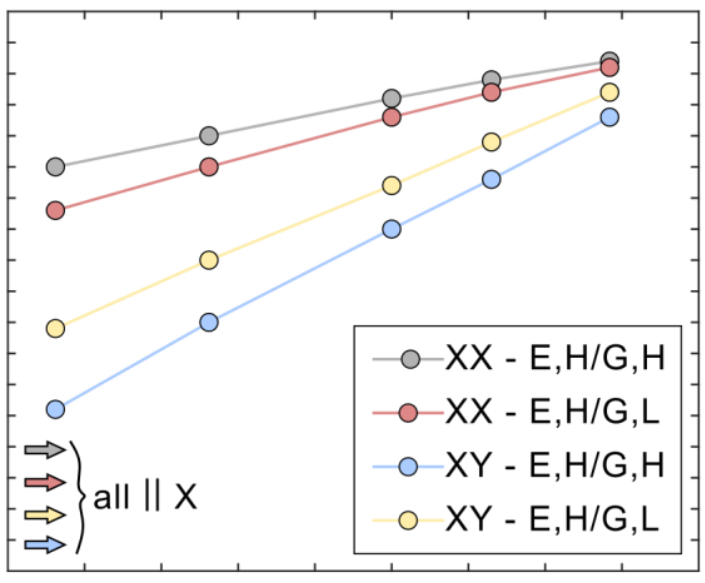

d) Unsheared ecl. breccia (100-m scale)

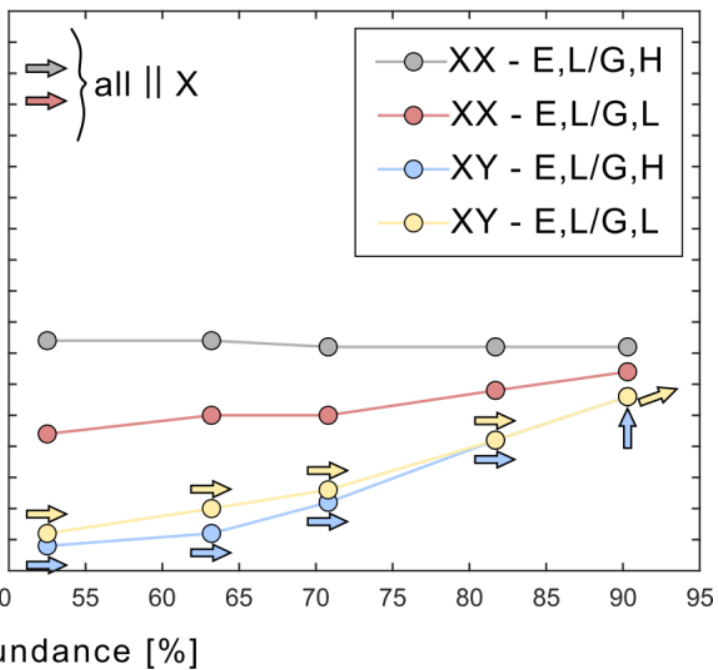

403

404

405

406

407

408

409

410

411

412

413

Fig. 5. P wave anisotropy of the FEM calculations: (a) Small-scale eclogite shear zones, (b) sheared eclogite breccia, (c) small-scale static eclogite, and (d) unsheared eclogite breccia. For a description of model types and explanation of the legend, refer to Fig. 4. Arrows indicate the direction of the fast axis of the effective medium with horizontal being in $\mathrm{x}$ direction and vertical in $\mathrm{y}$ direction.

Additionally, eclogitization on Holsnøy also proceeded statically without significant ductile deformation (Jamtveit et al., 2000; Zertani et al., 2019b). Here, eclogitization most commonly advances parallel to the granulite foliation. For this case, we also calculated 20 different examples, varying both the abundance of eclogite and the elastic properties of the granulite and the eclogite (Fig. 3b; Tab. 2). 
414 The resulting P wave velocities show a similar trend as those from the examples featuring small-

415 scale shear zones. Both the velocity of the fast and the slow axes increase linearly with

416 increasing abundance of eclogite (Fig. 4c). Further, the models featuring granulites with higher

417 anisotropy result in faster $\mathrm{P}$ wave velocities of the effective medium than the models

418 implementing lower-anisotropy granulites. Additionally, the $\mathrm{P}$ wave velocities are in the same

419 range as the ones calculated for small-scale shear zones.

420 The orientations of the fast and slow axes are typically constant with the fast axis being parallel

421 to the granulite foliation (horizontal) and the slow axis perpendicular. Only in the calculations

422 where the lower-anisotropy eclogite and granulite with the orientation of the fast axes

423 perpendicular to each other are implemented, the resulting orientation changes slightly. These

424 calculations indicate that the fast axis remains horizontal (i.e., parallel to the granulite foliation)

425 while the slow axis rotates slightly away from the initial vertical orientation.

426 The $\mathrm{P}$ wave anisotropy shows a variable trend comparing the different models. The medium

427 featuring the higher-anisotropy granulite, with both the fast axes of the granulite and eclogite

428 oriented parallel to each other result in a P wave anisotropy of $\sim 4 \%$ that essentially does not

429 change with varying eclogite abundance (Fig. 5d). The same is observed for the models featuring

430 the lower-anisotropy granulite with the fast axes of the granulite and eclogite being oriented

431 perpendicular to each other. Here, the resulting $\mathrm{P}$ wave velocity remains relatively constant

432 around $1-2 \%$.

433 In contrast, the resulting anisotropy of the other two model types changes with increasing

434 eclogite abundance. The sequence featuring a lower-anisotropy granulite with the fast axis

435 oriented parallel to the fast axis of the eclogite increases from $\sim 2 \%$ to $\sim 4 \%$, while the sequence 
436 featuring the higher-anisotropy granulite with the fast axes of the two rocks oriented

437 perpendicular to each other decreases from $\sim 3 \%$ to $<1 \%$.

$438 \quad 4.2$ P-wave velocity of eclogite breccia

439 With increasing degree of eclogitization the so-called eclogite breccia develops, which is

440 composed of an eclogite matrix that surrounds preserved blocks of granulite (Boundy et al.,

441 1992). On Holsnøy, the eclogite breccia can be divided into two endmember types (Zertani et al.,

442 2019b): The sheared eclogite breccia is characterized by a strongly sheared and foliated eclogite

443 matrix, while the matrix of the unsheared eclogite breccia is diffuse and less foliated.

444 We calculated 20 examples for each of the two types, varying the abundance of eclogite and the

445 elastic properties of the granulite and eclogite (Fig. 3c, d; Tab. 2). For all examples of the sheared

446 eclogite breccia, the $\mathrm{P}$ wave velocities increase linearly with increasing eclogite abundance. All

447 fast axes and all slow axes converge toward higher eclogite abundances, thus giving fairly

448 distinct maximum and minimum $\mathrm{P}$ wave velocities at high eclogite abundances that are

449 independent of the elastic properties of the granulite implemented in the model. (Fig. 4; Fig. 5).

450 The slope of the linear increase for the different models is similar to the models dealing with

451 small-scale shear zones. Further, the fast axis of the effective medium in all models is parallel to

452 the shear plane (horizontal) and the slow axis is perpendicular. Additionally, the $\mathrm{P}$ wave

453 velocities at $\sim 50 \%$ eclogite abundance agree well between the models for small-scale shear zones

454 and the sheared eclogite breccia at the same eclogite fraction.

455 As in the case of the small-scale shear zones, the P wave anisotropy calculated for the sheared

456 eclogite breccia increases nearly linearly with increasing eclogite abundance reaching 7-9\% at

$457 \sim 90 \%$. Further, P wave anisotropy is consistently higher for models where the fast axes of the

458 granulite and the eclogite are oriented parallel. In this scenario the anisotropy reaches its 
maximum when both the granulite and the eclogite have a high anisotropy. If the fast axis of the granulite, however, is perpendicular to the fast axis of the eclogite, the resulting anisotropy is higher when the implemented granulite has a lower anisotropy.

The $\mathrm{P}$ wave velocities calculated for the unsheared eclogite breccia show the same general trends as those for the sheared eclogite breccia (Fig. 4d). The only deviation results from the examples implementing granulite and eclogite with their anisotropy perpendicular to each other. Here the calculations result in a change of the orientation at high eclogite abundances.

The trends of the $\mathrm{P}$ wave anisotropy of the unsheared eclogite breccia in all calculated examples is lower than the comparable examples of the sheared eclogite breccia (Fig. 5). Most sequences, however, also slightly increase with increasing eclogite abundance, except for those where a lower-anisotropy eclogite is paired with the higher-anisotropy granulite, both of which have their fast axes parallel to each other. In that case the $\mathrm{P}$ wave anisotropy is nearly constant at $\sim 3.7 \%$ (Tab. 2).

\section{Discussion}

Many studies have calculated or measured $\mathrm{P}$ wave velocities of various metamorphic rocks with the aim of interpreting the results of large-scale geophysical imaging techniques (e.g., Almqvist \& Mainprice, 2017). However, the sample sizes used for these interpretations are typically far below the resolution of geophysical studies. It is thus essential to understand how geometries formed at depth during ongoing eclogitization shape the seismic properties of the effective medium in combination with the (anisotropic) seismic properties of the constituent rocks. We distinguish two geometrical contributing factors in order to characterize their influence separately. (1) The configuration that the different lithologies have to one another on the outcrop scale or larger. This includes, for example, eclogite shear zones that crosscut granulites. In the 
482 following, this will be referred to as external geometry, as it involves the relationship of the

483 lithologies to each other but not specifically the properties of the constituting lithologies

484 themselves. (2) The second contributing geometrical factor will be referred to as internal

485 geometry. It highlights the properties of the lithologies themselves by characterizing the

486 relationship between the directional dependence of the elastic properties of the different

487 lithologies that is caused by, for example, crystallographic preferred orientations (CPO) or shape

488 preferred orientations (SPO). The internal geometry thus distinguishes whether the fastest

489 velocity of the eclogite and granulite are parallel or oblique to each other.

$490 \quad 5.1$ Effective properties of $20 \mathrm{~m}$ and $100 \mathrm{~m}$ scale structures

491 Essentially, the $\mathrm{P}$ wave velocities calculated for the different geometrical setups show that the 492 velocities are controlled by the velocities of the constituent rocks and their proportions (Fig. 4,

493 Fig. 5). This has been accepted and applied by previous studies by calculating, for example,

494 Voigt-Reuss-Hill (VRH) averages (Hill, 1952) and linking those with the CPOs of the mineral

495 phases (e.g., Hacker et al., 2014; Llana-Funez \& Brown, 2012; Worthington et al., 2013). Most

496 of these studies, however, obtain information from the thin section scale to recognize crustal-

497 scale processes or to interpret the results from large-scale geophysical imaging studies. The

498 results presented in this study indicate that Voigt-Reuss-Hill averages calculated from outcrop-

499 scale features are sufficiently precise to estimate the effective properties on a variety of scales

500 (Fig. 4). Essentially, the external geometries that are representative of eclogitization of crustal

501 rocks have only limited influence on the resulting $\mathrm{P}$ wave velocities. Only in isolated cases the

502 velocities are modified, thus deviating from the calculated VRH averages (Fig. 4a and 4c). Here a

503 minor geometric effect is plausible, however, this effect results in a maximum modification of

$504<0.2 \mathrm{~km} \mathrm{~s}^{-1}$ of the $\mathrm{P}$ wave velocity and is thus negligible in the context of large-scale crustal 
processes. In fact, most studies that distinguish between the effect of CPO vs. SPO on the thin section scale conclude that the effect of SPO is negligible (e.g., Zhong et al., 2014), although there is evidence that at least in the deep mantle SPO does produce seismic anisotropy (Faccenda et al., 2019).

Furthermore, although Holsnøy serves as an example here, this observation can be transferred to other exposures of partial eclogitization and is thus likely representative in more general terms. The shear zones explored here, for example, constitute extreme cases of geometric arrangement as shear zones are well ordered and have a significant lateral extent. It could thus be expected that the influence of, for example, isolated eclogite boudins or blocks as reported from other exposures (e.g., John \& Schenk, 2003; Locatelli et al., 2019; Mørk, 1985) on effective P wave velocities would be even smaller.

However, P wave anisotropy varies between the different geometrical configurations (Fig. 5). In this context, our results reveal the importance of the internal geometry compared to that of the external geometry (Fig. 4, Fig. 5). As discussed above, the external geometry only has a minor effect on the $\mathrm{P}$ wave velocities and anisotropy of the effective medium. The variation of anisotropy for the different configurations tested by us are thus controlled by the internal geometry. The most important factor is the anisotropy of the constituent lithologies that are necessary to produce significant anisotropy of the effective medium. Additionally, the effective anisotropy is strengthened or weakened by the relationship of the individual anisotropies of the lithologies. Anisotropies are higher if the fast axes of the lithologies are aligned but not higher than the highest contributing anisotropy (Fig. 5). Further, our results demonstrate the predominance of the higher-anisotropy lithology. The fast axis of the effective medium is parallel to the anisotropy of the matrix lithology (i.e., in line with the fabric of granulite or 
528 eclogite), if the difference in anisotropy between the lithologies is small, or parallel to the higher-

529 anisotropy lithology, even if this lithology is less abundant (Fig. 5). This means a strongly

530 deformed rock, such as eclogite in shear zones, controls the overall anisotropy even at low

531 abundances. The predominance of the higher-anisotropy phase has also been demonstrated on

532 the rock scale considering, for example, the alignment of mica (e.g., Naus-Thijssen, et al., 533 2011b).

$534 \quad 5.2$ Effective properties on the kilometer scale

535 Combining our results with field observations provides the opportunity to understand how partial 536 eclogitization of crustal rocks alters the seismic properties on a scale significantly larger than 537 what can be measured in the laboratory. Our results suggest that $\mathrm{P}$ wave velocities are almost 538 entirely controlled by the velocities and abundances of the constituting rocks (Fig. 4). Essentially, 539 there is no difference in the $\mathrm{P}$ wave velocities between rocks that have formed through static 540 eclogitization and those that formed while undergoing ductile deformation. Neither the finite 541 geometries nor the intrinsic seismic anisotropy of the granulites and eclogites have a significant 542 impact on the resulting isotropic average bulk velocities and the variations that can be 543 distinguished are minor. The $\mathrm{P}$ wave anisotropy, however, is influenced strongly by the 544 anisotropy of the rocks that form the effective medium (Fig. 5). Further, our results show that the 545 rock with the higher anisotropy controls bulk anisotropy. In any case, the exemplary geometries 546 discussed above are still far smaller than what can be resolved with large-scale geophysical 547 methods.

548 Therefore, we used these results to extract bulk properties of the effective medium at a scale that 549 could be resolved by large-scale geophysical imaging (Fig. 6). Accordingly, we used an area on 550 Holsnøy that is $\sim 3.9$-by-4.6 km in size (Fig. 1 and Fig. 6a) and provides a coherent natural 
laboratory for eclogitization related structures. The geometries are based on the map shown in Zertani et al. (2019b). As properties for the different map units we implemented the resulting elastic tensor of the examples shown above, choosing one representative example for each of the geometric configurations, i.e., sheared eclogite breccia at $~ 75 \%$ eclogite with the fast axis of higher-anisotropy eclogite and higher-anisotropy granulite parallel to each other and unsheared eclogite breccia at $\sim 71 \%$ eclogite with the fast axis of the lower-anisotropy eclogite and the higher-anisotropy granulite parallel to each other (Tab. 2). For pure eclogite and granulite we chose the higher-anisotropy versions (Tab. 1) that were also used for the calculations discussed above (Zertani et al., 2019a). The elastic tensors were rotated so that the fast axis is parallel to the structures presented by Zertani et al. (2019b).

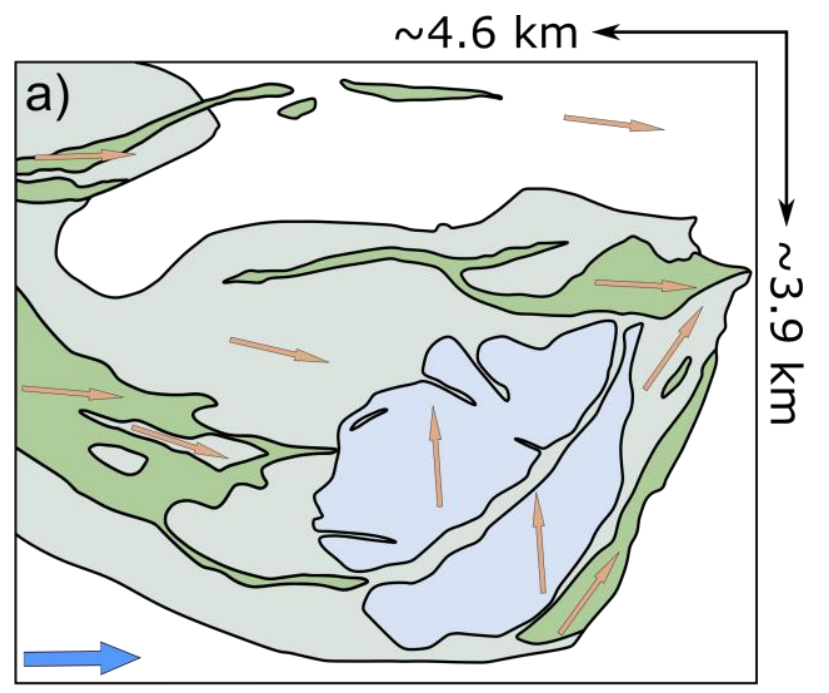

Granulite
Granulite with small-scale eclogite shear zones
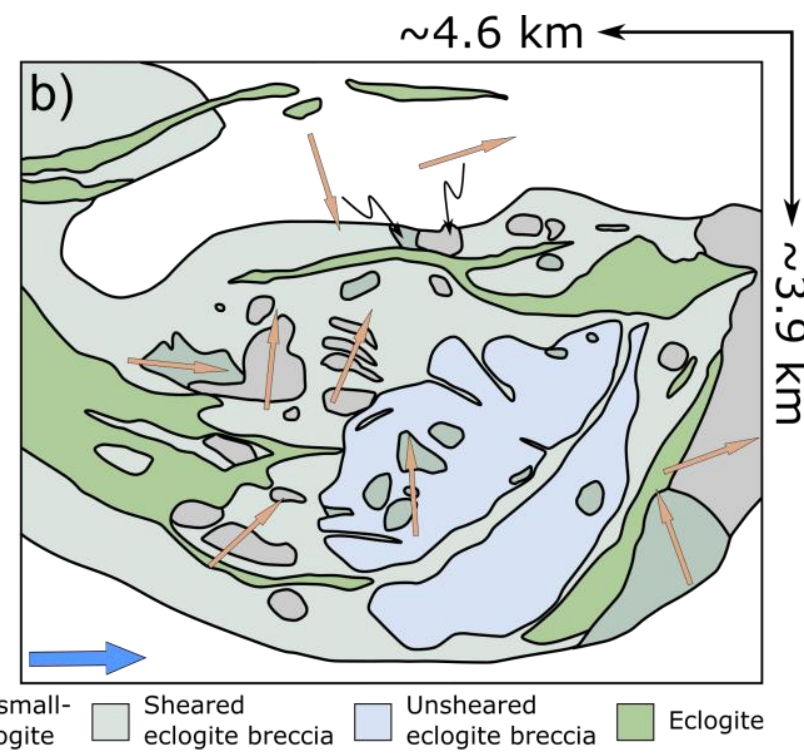

Direction of fast axis $\Longrightarrow$ Direction of resulting fast axis

Fig. 6. Geometries used for the FEM calculations on the kilometer-scale. (a) Simpler model without smaller-scale structures. (b) More realistic model with small-scale structures. The location of this figure is given in Fig. 1. The yellow arrows indicate the direction of the fast axis implemented for the different lithologies. The blue arrows show the direction of the fastest velocity for each of the models.

Additionally, we implemented a second (more precise) model that also includes smaller-scale structures (Fig. 6b). Here we implemented the small-scale eclogite shear zones at $\sim 31 \%$ eclogite 
with the lower-anisotropy granulite and the higher-anisotropy eclogite (Tab. 2) and the smallscale static eclogite at $\sim 32 \%$ eclogite with the higher-anisotropy granulite and the loweranisotropy eclogite (Tab. 2).

The resulting $\mathrm{P}$ wave velocities of both models are in the range of $8.0 \mathrm{~km} \mathrm{~s}^{-1}$ (fast axis) to $7.7 \mathrm{~km}$ $\mathrm{s}^{-1}$ (slow axis), i.e., within the expected range of the measured $\mathrm{P}$ wave velocities between granulite and eclogite (Zertani et al., 2019a). Similar velocities are also reported from geophysical studies dealing with active convergent settings, typically in the range of $7-8 \mathrm{~km} \mathrm{~s}^{-1}$ (e.g., Nabelek et al., 2009; Schulte-Pelkum et al., 2005; Sippl et al., 2013). Additionally, our calculation predicts a $\mathrm{P}$ wave anisotropy of $3.9 \%$ for the simpler model (Fig. $6 \mathrm{a}$ ) and $3.3 \%$ for the model that includes the small-scale structures (Fig. 6b). These values are in the range of what is generally reported from eclogites and granulites (e.g., Brown et al., 2009; Worthington et al., 2013). However, it has to be noted that the anisotropy presented here is representative for the effective medium on a kilometer-scale and not only for single (handspecimen-sized) samples. 5.3 Implications for imaging of continental collision

The exposures on Holsnøy have been studied extensively because they provide a rare example to study partial eclogitization of a coherent piece of continental crust (e.g., Austrheim 1987, Bjørnerud et al., 2002; Jamtveit et al., 1990; 2000; Jolivet et al., 2005). These exposures are also widely considered as representative of how crustal rocks transform to eclogites (e.g., Austrheim, 1990). Specifically, Holsnøy is often regarded as an ideal analog to the underplating crust of India below the Himalaya (e.g., Jamtveit et al., 2019; Labrousse et al., 2010).

$\mathrm{P}$ wave velocities below the Tibetan plateau are suggested to be $>7.0 \mathrm{~km} \mathrm{~s}^{-1}$, which was interpreted to represent $\sim 30 \%$ eclogitization (Schulte-Pelkum et al., 2005). Our calculation for Holsnøy is representative of $\sim 50 \%$ eclogitization and yields slightly higher velocities. It thus 
seems possible to estimate the degree of eclogitization based on $\mathrm{P}$ wave velocities. However, this is only feasible if the backazimuthal distribution is sufficiently representative (Nabelek et al., 2009; Schulte-Pelkum et al., 2005).

The retrieved P wave anisotropy of 3-4\% from our model is sufficiently high that it could result in a backazimuthal dependence of the retrieved signal in seismological studies. Additionally, our calculations of $\mathrm{P}$ wave anisotropy of the different structural associations that could be expected in a partially eclogitized crust show how different geometries can cause high P-wave anisotropy (Fig. 5). In the Himalaya-Tibet collision system, where the lower crust of India is imaged below the Himalaya (Jackson et al., 2004; Labrousse et al., 2010), using the receiver function method, it has been shown that the retrieved signal of the Moho is sharp using earthquakes coming from the north, while the Moho cannot be clearly imaged using earthquakes arriving from the south, suggesting an anisotropic fabric within the buried crust (Nabelek et al., 2009; Schulte-Pelkum et al., 2005). Nabelek et al. (2009) propose that this fabric is caused by the imbrication and rotation of a stratified lower crust, excluding eclogites as the cause for the anisotropy because eclogites typically have anisotropies $<4 \%$. However, our results show that partial eclogitization of the lower crust does indeed produce considerable anisotropies at the scale sampled by geophysical imaging techniques. Moreover, as shown by our results the effect of external geometry on seismic anisotropy is limited suggesting that simple layering or imbrication might not produce sufficient seismic anisotropy on this scale. Our results provide an alternative explanation for the structures observed below the Himalaya. We suggest that considering the $\mathrm{P}$ wave velocities reported and the backazimuthal dependence (Nabelek et al., 2009; Schulte-Pelkum et al., 2005) eclogitization of the crust along ductile shear zones, similar to those exposed on Holsnøy seems the more likely explanation. 
Additionally, both kilometer-scale models we present here suggest that the fast axis of the shear zone system is oriented WNW-ESE. At least in a qualitative sense this suggests that during ongoing eclogitization, when this anisotropy was established it was dipping toward the upper plate as is also evidenced by the top-east kinematics of the shear zone system (Jolivet et al., 2005; Raimbourg et al., 2005). Geophysical imaging suggests a northward dipping fabric within the lower Indian crust (Nabelek et al., 2009; Schulte-Pelkum et al., 2005), that is, dipping toward the Asian plate, consistent with a top to the south shear sense. Our results demonstrate that propagating eclogite-facies shear zones would produce a fabric and subsequent anisotropy with a similar orientation. The scale of those shear zones is actually a minor issue, since our results show the same dependence of effective medium properties on constitutive lithologies independent of the scale.

\subsection{Implications for oceanic subduction}

Although the rocks on Holsnøy originate from continental crust some implications for oceanic subduction settings can nevertheless be explored. In many geophysical studies of subducting oceanic plates the descending crust is clearly imaged at shallow depth but loses its seismic signal at greater depth (e.g., Bostock et al., 2002; Pearce et al., 2012; Rondenay et al., 2008; Yuan et al., 2000). This decrease of the seismic signal is typically interpreted as due to a decreased impedance contrast between descending crust and mantle rocks caused by eclogitization. This is often accompanied by an increase of the dip angle in the Wadati-Benioff zone that indicates a kink in the slab geometry (e.g., Halpaap et al., 2018; Klemd et al., 2011; Yuan et al., 2000). While the subducting crust is invisible to seismological studies at this point its presence is evidenced by the Wadati-Benioff zone and the inferred kink of the slab has been proposed as a 
639 possible geometric obstacle that inhibits exhumation of crustal material subducted beyond that

640 point and is therefore potentially vital to understand subduction zone processes (Klemd et al.,

641 2011). Additionally, kinking on this scale must cause internal deformation of the subducting

642 slab. Whether or not this deformation is localized or homogeneously distributed and how this

643 deformation process affects ongoing eclogitization of the slab is enigmatic. However, utilizing

644 seismic anisotropy and the subsequent backazimuthal bias on the retrieved seismic signal might

645 prove a powerful tool to unravel these processes in active subduction zones. In this context,

646 although reliable imaging of the crustal anisotropy at these depths is still challenging, seismic

647 anisotropy of the subducted oceanic crust might make it possible to image it to larger depth and

648 illuminate an otherwise invisible slab.

649

650

\section{Conclusions}

651 We calculated $\mathrm{P}$ wave velocities and the corresponding $\mathrm{P}$ wave anisotropy for various

652 geometries, which are representative of partially eclogitized crust. The results show that dynamic

653 eclogitization, associated with shear zone formation, can cause a high $\mathrm{P}$ wave anisotropy that

654 increases with increasing eclogitization. The anisotropy of the effective medium is generally

655 controlled by the anisotropy of the matrix or by the contributing lithology that has the highest

656 anisotropy, even if this lithology is less abundant than the other contributors. Consequently,

657 patches of static eclogitization produce a comparatively low $\mathrm{P}$ wave anisotropy, which is in some

658 cases independent of the amount of eclogitization. The (external) geometric configuration of the

659 lithologies has little to no effect on the seismic properties of the effective medium.

660 Our results link partial eclogitization with geophysical observations at active convergent plate

661 boundaries. Previously, significant anisotropy due to eclogitization in deeply buried or subducted 
662 crust has been excluded as eclogites are typically not strongly anisotropic. Contrary to this, our

663 results demonstrate that significant anisotropy due to partial eclogitization of crustal material on

664 a kilometer-scale is a likely explanation for the discrepancy of the signals retrieved from

665 different backazimuths in seismological studies. For example, the structures seen below the

666 Himalaya are likely anisotropic due to the formation of eclogite-facies shear zones within the

667 lower Indian crust. Additionally, our results strongly encourage the utilization of seismic

668 anisotropy as a tool to visualize the structural associations at depth, thus aiding the extraction of

669 the underlying mechanisms active during ongoing eclogitization of crustal material.

670

671

672

673

674

675

676

677

678

679

680

681

682

683

684

685

686

687

\section{Acknowledgements}

This research was supported by the Deutsche Forschungsgemeinschaft (DFG) in the framework of the priority program SPP 2017 “Mountain Building in Four Dimensions (MB-4D)” by grant

JO 349/11-1. Funding for TBA was provided from Norges forskningsråd (NFR) project 250327.

We would like to thank Whitney Behr and one anonymous reviewer for their thorough and thoughtful reviews and Maureen Long for editorial handling. Input data for the calculations are provided as figures in the supporting information and will be uploaded to the OSF data repository (osf.io) after acceptance.

\section{References}
Almqvist, B. S. G., \& Mainprice, D. (2017). Seismic properties and anisotropy of the continental crust: Predictions based on mineral texture and rock microstructure. Reviews of Geophysics, 55(2), 367-433. https://doi.org/10.1002/2016RG000552
Andersen, T. B., Corfu, F., Labrousse, L., \& Osmundsen, P.-T. (2012). Evidence for hyperextension along the pre-Caledonian margin of Baltica. Journal of the Geological Society, 169(5), 601-612. https://doi.org/10.1144/0016-76492012-011 
Angiboust, S., Agard, P., Raimbourg, H., Yamato, P., \& Huet, B. (2011). Subduction interface processes recorded by eclogite-facies shear zones (Monviso, W. Alps). Lithos, 127(1), 222-238. https://doi.org/10.1016/j.lithos.2011.09.004

Austrheim, H. (1987). Eclogitization of lower crustal granulites by fluid migration through shear zones. Earth and Planetary Science Letters, 81(2), 221-232. https://doi.org/10.1016/0012-821X(87)90158-0

Austrheim, H. (1990). The granulite-eclogite facies transition: A comparison of experimental work and a natural occurrence in the Bergen Arcs, western Norway. Lithos, 25(1), 163169. https://doi.org/10.1016/0024-4937(90)90012-P

Austrheim, H. (1991). Eclogite formation and dynamics of crustal roots under continental collision zones. Terra Nova, 3(5), 492-499. https://doi.org/10.1111/j.13653121.1991.tb00184.x

Austrheim, H., \& Griffin, W. L. (1985). Shear deformation and eclogite formation within granulite-facies anorthosites of the Bergen Arcs, western Norway. Chemical Geology, 50(1), 267-281. https://doi.org/10.1016/0009-2541(85)90124-X

Backus, G. E. (1962). Long-wave elastic anisotropy produced by horizontal layering. Journal of Geophysical Research, 67(11), 4427-4440. https://doi.org/10.1029/JZ067i011p04427

Bascou, J., Barruol, G., Vauchez, A., Mainprice, D., \& Egydio-Silva, M. (2001). EBSDmeasured lattice-preferred orientations and seismic properties of eclogites. Tectonophysics, 342(1), 61-80. https://doi.org/10.1016/S0040-1951(01)00156-1

Bhowany, K., Hand, M., Clark, C., Kelsey, D. E., Reddy, S. M., Pearce, M. A., et al. (2018). Phase equilibria modelling constraints on $\mathrm{P}-\mathrm{T}$ conditions during fluid catalysed conversion of granulite to eclogite in the Bergen Arcs, Norway. Journal of Metamorphic Geology, 36(3), 315-342. https://doi.org/10.1111/jmg.12294

Bjørnerud, M. G., Austrheim, H., \& Lund, M. G. (2002). Processes leading to eclogitization (densification) of subducted and tectonically buried crust. Journal of Geophysical Research: Solid Earth, 107(B10), ETG 14-11-ETG 14-18. https://doi.org/10.1029/2001JB000527

Bloch, W., John, T., Kummerow, J., Salazar, P., Krüger, O. S., \& Shapiro, S. A. (2018). Watching Dehydration: Seismic Indication for Transient Fluid Pathways in the Oceanic Mantle of the Subducting Nazca Slab. Geochemistry, Geophysics, Geosystems, 19, 31893207. https://doi.org/10.1029/2018GC007703

Bostock, M., Hyndman, R., Rondenay, S., \& Peacock, S. (2002). An inverted continental Moho and serpentinization of the forearc mantle. Nature, 417, 536-538. https://doi.org/10.1038/417536a

Bostock, M. G. (2013). The Moho in subduction zones. Tectonophysics, 609, 547-557. https://doi.org/10.1016/j.tecto.2012.07.007

Boundy, T. M., Fountain, D. M., \& Austrheim, H. (1992). Structural development and petrofabrics of eclogite facies shear zones, Bergen Arcs, western Norway: implications for deep crustal deformational processes. Journal of Metamorphic Geology, 10(2), 127146. https://doi.org/10.1111/j.1525-1314.1992.tb00075.x

Boundy, T. M., Mezger, K., \& Essene, E. J. (1997). Temporal and tectonic evolution of the granulite-eclogite association from the Bergen Arcs, western Norway. Lithos, 39(3), 159178. https://doi.org/10.1016/S0024-4937(96)00026-6

Brown, D., Llana-Funez, S., Carbonell, R., Alvarez-Marron, J., Marti, D., \& Salisbury, M. (2009). Laboratory measurements of P-wave and S-wave velocities across a surface 
analog of the continental crust-mantle boundary: Cabo Ortegal, Spain. Earth and Planetary Science Letters, 285(1-2), 27-38. https://doi.org/10.1016/j.epsl.2009.05.032

Brownlee, S. J., Schulte-Pelkum, V., Raju, A., Mahan, K., Condit, C., \& Orlandini, O. F. (2017). Characteristics of deep crustal seismic anisotropy from a compilation of rock elasticity tensors and their expression in receiver functions. Tectonics, 36(9), 1835-1857. https://doi.org/10.1002/2017tc004625

Corfu, F., Andersen, T. B., \& Gasser, D. (2014). The Scandinavian Caledonides: main features, conceptual advances and critical questions. Geological Society, London, Special Publications, 390(1), 9-43. https://doi.org/10.1144/sp390.25

Dewey, J. F., Ryan, P. D., \& Andersen, T. B. (1993). Orogenic uplift and collapse, crustal thickness, fabrics and metamorphic phase changes: the role of eclogites. Geological Society, London, Special Publications, 76(1), 325-343. https://doi.org/10.1144/GSL.SP.1993.076.01.16

Faccenda, M., Ferreira, A. M. G., Tisato, N., Lithgow-Bertelloni, C., Stixrude, L., \& Pennacchioni, G. (2019). Extrinsic Elastic Anisotropy in a Compositionally Heterogeneous Earth's Mantle. Journal of Geophysical Research: Solid Earth, 124, 16711687. https://doi.org//10.1029/2018JB016482

Fountain, D. M., Boundy, T. M., Austrheim, H., \& Rey, P. (1994). Eclogite-facies shear zonesdeep crustal reflectors? Tectonophysics, 232(1), 411-424. https://doi.org/10.1016/00401951(94)90100-7

Glodny, J., Kühn, A., \& Austrheim, H. (2008). Geochronology of fluid-induced eclogite and amphibolite facies metamorphic reactions in a subduction-collision system, Bergen Arcs, Norway. Contributions to Mineralogy and Petrology, 156(1), 27-48. https://doi.org/10.1007/s00410-007-0272-y

Hacker, B., Ritzwoller, M., \& Xie, J. (2014). Partially melted, mica-bearing crust in Central Tibet. Tectonics, 33(7), 1408-1424. https://doi.org/10.1002/2014TC003545

Halpaap, F., Rondenay, S., \& Ottemöller, L. (2018). Seismicity, Deformation, and Metamorphism in the Western Hellenic Subduction Zone: New Constraints From Tomography. Journal of Geophysical Research: Solid Earth, 123(4), 3000-3026. https://doi.org/10.1002/2017JB015154

Hetényi, G., Cattin, R., Brunet, F., Bollinger, L., Vergne, J., Nábělek, J. L., \& Diament, M. (2007). Density distribution of the India plate beneath the Tibetan plateau: Geophysical and petrological constraints on the kinetics of lower-crustal eclogitization. Earth and Planetary Science Letters, 264(1-2), 226-244. https://doi.org/10.1016/j.eps1.2007.09.036

Hetzel, R., Echtler, H. P., Seifert, W., Schulte, B. A., \& Ivanov, K. S. (1998). Subduction- and exhumation-related fabrics in the Paleozoic high-pressure-low-temperature Maksyutov Complex, Antingan area, southern Urals, Russia. GSA Bulletin, 110(7), 916-930. https://doi.org/10.1130/0016-7606(1998)110<0916:SAERFI>2.3.CO;2

Hill, R. (1952). The elastic behaviour of a crystalline aggregate. Proceedings of the Physical Society. Section A, 65(5), 349-354.

Hudson, J. A. (1981). Wave speeds and attenuation of elastic waves in material containing cracks. Geophysical Journal International, 64(1), 133-150. https://doi.org/10.1111/j.1365-246X.1981.tb02662.x

Jackson, J. A., Austrheim, H., McKenzie, D., \& Priestley, K. (2004). Metastability, mechanical strength, and the support of mountain belts. Geology, 32(7), 625-628. https://doi.org/10.1130/g20397.1 
Jakob, J., Andersen, T. B., \& Kjøll, H. J. (2019). A review and reinterpretation of the architecture of the South and South-Central Scandinavian Caledonides-A magma-poor to magma-rich transition and the significance of the reactivation of rift inherited structures. Earth-Science Reviews, 192, 513-528. https://doi.org/10.1016/j.earscirev.2019.01.004

Jamtveit, B., Austrheim, H., \& Malthe-Sorenssen, A. (2000). Accelerated hydration of the Earth's deep crust induced by stress perturbations. Nature, 408(6808), 75-78. https://doi.org/10.1038/35040537

Jamtveit, B., Bucher-Nurminen, K., \& Austrheim, H. (1990). Fluid controlled eclogitization of granulites in deep crustal shear zones, Bergen arcs, Western Norway. Contributions to Mineralogy and Petrology, 104(2), 184-193. https://doi.org/10.1007/bf00306442

Jamtveit, B., Petley-Ragan, A., Incel, S., Dunkel, K. G., Aupart, C., Austrheim, H., et al. (2019). The effects of earthquakes and fluids on the metamorphism of the lower continental crust. Journal of Geophysical Research: Solid Earth, 124(8). https://doi.org/10.1029/2018jb016461

John, T., \& Schenk, V. (2003). Partial eclogitisation of gabbroic rocks in a late Precambrian subduction zone (Zambia): prograde metamorphism triggered by fluid infiltration. Contributions to Mineralogy and Petrology, 146(2), 174-191. https://doi.org/10.1007/s00410-003-0492-8

Jolivet, L., Raimbourg, H., Labrousse, L., Avigad, D., Leroy, Y., Austrheim, H., \& Andersen, T. B. (2005). Softening trigerred by eclogitization, the first step toward exhumation during continental subduction. Earth and Planetary Science Letters, 237(3-4), 532-547. https://doi.org/10.1016/j.epsl.2005.06.047

Kawakatsu, H. (2016). A new fifth parameter for transverse isotropy. Geophysical Journal International, 204(1), 682-685. https://doi.org/10.1093/gji/ggv479

Kern, H. (1978). The effect of high temperature and high confining pressure on compressional wave velocities in quartz-bearing and quartz-free igneous and metamorphic rocks. Tectonophysics, 44(1), 185-203. https://doi.org/10.1016/0040-1951(78)90070-7

Kern, H., Gao, S., \& Liu, Q.-S. (1996). Seismic properties and densities of middle and lower crustal rocks exposed along the North China Geoscience Transect. Earth and Planetary Science Letters, 139(3), 439-455. https://doi.org/10.1016/0012-821X(95)00240-D

Kim, D., Keranen, K. M., Abers, G. A., \& Brown, L. D. (2019). Enhanced Resolution of the Subducting Plate Interface in Central Alaska From Autocorrelation of Local Earthquake Coda. Journal of Geophysical Research: Solid Earth, 124(2), 1583-1600. https://doi.org/10.1029/2018jb016167

Kind, R., Yuan, X., \& Kumar, P. (2012). Seismic receiver functions and the lithosphereasthenosphere boundary. Tectonophysics, 536-537, 25-43. https://doi.org/10.1016/j.tecto.2012.03.005

Klemd, R., John, T., Scherer, E. E., Rondenay, S., \& Gao, J. (2011). Changes in dip of subducted slabs at depth: Petrological and geochronological evidence from HP-UHP rocks (Tianshan, NW-China). Earth and Planetary Science Letters, 310(1-2), 9-20. https://doi.org/10.1016/j.epsl.2011.07.022

Labrousse, L., Hetényi, G., Raimbourg, H., Jolivet, L., \& Andersen, T. B. (2010). Initiation of crustal-scale thrusts triggered by metamorphic reactions at depth: Insights from a comparison between the Himalayas and Scandinavian Caledonides. Tectonics, 29(5), TC5002. https://doi.org/10.1029/2009TC002602 
Llana-Funez, S., \& Brown, D. (2012). Contribution of crystallographic preferred orientation to seismic anisotropy across a surface analog of the continental Moho at Cabo Ortegal, Spain. Geological Society of America Bulletin, 124(9-10), 1495-1513. https://doi.org/10.1130/b30568.1

Locatelli, M., Federico, L., Agard, P., \& Verlaguet, A. (2019). Geology of the southern Monviso metaophiolite complex (W-Alps, Italy). Journal of Maps, 15(2), 283-297. https://doi.org/10.1080/17445647.2019.1592030

Mavko, G., Mukerji, T., \& Dvorkin, J. (2009). The rock physics handbook: Tools for seismic analysis of porous media: Cambridge university press.

Nabelek, J., Hetenyi, G., Vergne, J., Sapkota, S., Kafle, B., Jiang, M., et al. (2009). Underplating in the Himalaya-Tibet collision zone revealed by the Hi-CLIMB experiment. Science, 325(5946), 1371-1374. https://doi.org/10.1126/science.1167719

Mørk, M. B. E. (1985). A gabbro to eclogite transition on Flemsøy, Sunnmøre, western Norway. Chemical Geology, 50(1), 283-310. https://doi.org/10.1016/0009-2541(85)90125-1

Naus-Thijssen, F. M. J., Goupee, A. J., Johnson, S. E., Vel, S. S., \& Gerbi, C. (2011a). The influence of crenulation cleavage development on the bulk elastic and seismic properties of phyllosilicate-rich rocks. Earth and Planetary Science Letters, 311(3), 212-224. https://doi.org/10.1016/j.epsl.2011.08.048

Naus-Thijssen, F. M. J., Goupee, A. J., Vel, S. S., \& Johnson, S. E. (2011b). The influence of microstructure on seismic wave speed anisotropy in the crust: computational analysis of quartz-muscovite rocks. Geophysical Journal International, 185(2), 609-621. https://doi.org/10.1111/j.1365-246X.2011.04978.x

Okaya, D., Vel, S. S., Song, W. J., \& Johnson, S. E. (2019). Modification of crustal seismic anisotropy by geological structures ("structural geometric anisotropy"). Geosphere, 15(1), 146-170. https://doi.org/10.1130/GES01655.1

Pearce, F. D., Rondenay, S., Sachpazi, M., Charalampakis, M., \& Royden, L. H. (2012). Seismic investigation of the transition from continental to oceanic subduction along the western Hellenic Subduction Zone. Journal of Geophysical Research: Solid Earth, 117, B07306. https://doi.org/10.1029/2011JB009023

Pleuger, J., Froitzheim, N., \& Jansen, E. (2005). Folded continental and oceanic nappes on the southern side of Monte Rosa (western Alps, Italy): Anatomy of a double collision suture. Tectonics, 24(4). https://doi.org/10.1029/2004TC001737

Raimbourg, H., Jolivet, L., Labrousse, L., Leroy, Y., \& Avigad, D. (2005). Kinematics of syneclogite deformation in the Bergen Arcs, Norway: implications for exhumation mechanisms. Geological Society, London, Special Publications, 243(1), 175-192. https://doi.org/10.1144/gsl.sp.2005.243.01.13

Rondenay, S., Abers, G. A., \& van Keken, P. E. (2008). Seismic imaging of subduction zone metamorphism. Geology, 36(4), 275-278. https://doi.org/10.1130/G24112A.1

Saenger, E. H., Krüger, O. S., \& Shapiro, S. A. (2004). Effective elastic properties of randomly fractured soils: 3D numerical experiments. Geophysical Prospecting, 52(3), 183-195. https://doi.org/10.1111/j.1365-2478.2004.00407.x

Scambelluri, M., Müntener, O., Hermann, J. r., Piccardo, G. B., \& Trommsdorff, V. (1995). Subduction of water into the mantle: History of an Alpine peridotite. Geology, 23(5), 459-462. https://doi.org/10.1130/0091-7613(1995)023<0459:SOWITM>2.3.CO;2 
Schneider, F. M., Yuan, X., Schurr, B., Mechie, J., Sippl, C., Haberland, C., et al. (2013). Seismic imaging of subducting continental lower crust beneath the Pamir. Earth and Planetary Science Letters, 375, 101-112. https://doi.org/10.1016/j.epsl.2013.05.015 Schulte-Pelkum, V., Monsalve, G., Sheehan, A., Pandey, M. R., Sapkota, S., Bilham, R., \& Wu, F. (2005). Imaging the Indian subcontinent beneath the Himalaya. Nature, 435(7046), 1222-1225. https://doi.org/10.1038/nature03678

Shewchuk, J. R. (1996). Triangle: Engineering a 2D quality mesh generator and Delaunay triangulator. In M. C. Lin \& D. Manocha (Eds.), Applied Computational Geometry Towards Geometric Engineering (Vol. 1148, pp. 203-222). Berlin, Heidelberg: Springer Berlin Heidelberg.

Sippl, C., Schurr, B., Tympel, J., Angiboust, S., Mechie, J., Yuan, X., et al. (2013). Deep burial of Asian continental crust beneath the Pamir imaged with local earthquake tomography. Earth and Planetary Science Letters, 384, 165-177. https://doi.org/10.1016/j.epsl.2013.10.013

Vel, S. S., Cook, A. C., Johnson, S. E., \& Gerbi, C. (2016). Computational homogenization and micromechanical analysis of textured polycrystalline materials. Computer Methods in Applied Mechanics and Engineering, 310, 749-779. https://doi.org/10.1016/j.cma.2016.07.037

Worthington, J. R., Hacker, B. R., \& Zandt, G. (2013). Distinguishing eclogite from peridotite: EBSD-based calculations of seismic velocities. Geophysical Journal International, 193(1), 489-505. https://doi.org/10.1093/gji/ggt004

Yamato, P., Duretz, T., \& Angiboust, S. (2019). Brittle/ductile deformation of eclogites: insights from numerical models. Geochemistry, Geophysics, Geosystems, 20, 3116-3133. https://doi.org/10.1029/2019gc008249

Yuan, X., Sobolev, S. V., Kind, R., Oncken, O., Bock, G., Asch, G., et al. (2000). Subduction and collision processes in the Central Andes constrained by converted seismic phases. Nature, 408, 958-961. https://doi.org/10.1038/35050073

Zertani, S., John, T., Tilmann, F., Motra, H. B., Keppler, R., Andersen, T. B., \& Labrousse, L. (2019a). Modification of the seismic properties of subducting continental crust by eclogitization and deformation processes. Journal of Geophysical Research: Solid Earth, 124, 9731-9754. https://doi.org/10.1029/2019jb017741

Zertani, S., Labrousse, L., John, T., Andersen, T. B., \& Tilmann, F. (2019b). The Interplay of Eclogitization and Deformation During Deep Burial of the Lower Continental Crust-A Case Study From the Bergen Arcs (Western Norway). Tectonics, 38(3), 898-915. https://doi.org/10.1029/2018tc005297

Zhong, X., Andersen, N. H., Dabrowski, M., \& Jamtveit, B. (2019). Zircon and quartz inclusions in garnet used for complementary Raman thermobarometry: application to the Holsnøy eclogite, Bergen Arcs, Western Norway. Contributions to Mineralogy and Petrology, 174(6), 50. https://doi.org/10.1007/s00410-019-1584-4

Zhong, X., Frehner, M., Kunze, K., \& Zappone, A. (2014). A novel EBSD-based finite-element wave propagation model for investigating seismic anisotropy: Application to Finero Peridotite, Ivrea-Verbano Zone, Northern Italy. Geophysical Research Letters, 41(20), 7105-7114. https://doi.org/10.1002/2014GL060490 